\title{
A review of adaptive neural control applied to proton exchange membrane fuel cell systems
}

\author{
Christophe Lin-Kwong-Chon ${ }^{\mathrm{a}, *}$, Brigitte Grondin-Pérez ${ }^{\mathrm{a}}$, Jean-Jacques Amangoua Kadjo ${ }^{\mathrm{a}}$, Cédric Damour ${ }^{\mathrm{a}}$, Michel Benne ${ }^{\mathrm{a}}$ \\ ${ }^{a}$ LE2P, EA 4079, University of La Réunion, 15 Av. René Cassin, BP 7151, 97715 Saint-Denis, France
}

\begin{abstract}
Proton exchange membrane fuel cell systems are promising technologies for the integration of renewable energy. They pave the way for further emission-reduction and energy autonomy initiatives. However, widespread commercialization still faces several challenges to extend their durability, improve their reliability while reducing their cost. Control strategies included information about the state of heath are among promising levers to tackle these challenges. In this context, an active fault tolerant control strategy based on three modules is introduced. Firstly, a fault diagnosis tool identify the system state of health and detect abnormal conditions. Then, a decision process based on diagnosis results, manages to find a fault strategy mitigation. Finally, a set of controllers, or a re-configurable controller, are used to apply the decision strategy. This third module has to be suited to the realtime specifications of the system. In this context, neural networks-based controllers with adaptive learning appear to be especially appropriate methods for system state of health consideration. For this reason, this paper aims to bring a literature review for adaptive neural-based control applied on proton exchange membrane fuel cell systems. Based on this overview of recent works available, propositions are made to fill the resource gaps about fuel cell control and give some answers to the aforementioned issues.
\end{abstract}

Keywords: Proton exchange membrane fuel cell, Active fault tolerant control, Adaptive neural control, Learning Algorithms

\section{Introduction}

Storing intermittent energies, like solar or wind, is an important aspect in the expansion of renewable energies. Proton Exchange Membrane Fuel Cell (PEMFC) and hydrogen fuel have undeniable advantages compared to gasoline engine or batteries. The hydrogen fuel produced from electrolysis and carbonfree electricity can eliminate greenhouse gases over the whole cycle [1]. Moreover, hydrogen has one of the highest energy density and the fuel required for the PEMFC operation can be stored in external tanks. Whatever the storage forms, new facilities developing to improve safety, refueling and high volumetric energy density criteria [2-5]. Recent studies focused on Membrane Electrode Assembly (MEA), which is the main part of the system, with the aim of continuously improving its performance $[6,7]$. The latest investigations on the conception and manufacture of the Gas Diffusion Layer (GDL) provide a rise of the current density and extend the cell lifespan [8-10]. Likewise, there is growing interest concerning the end life strategies of the PEMFC system. The intended benefits lie in recovering of valuable catalysts (platinium and ruthenium) while allowing the additional recovery of other relevant materials such as the

${ }^{*}$ Corresponding author at: LE2P, EA 4079, University of La Réunion, 15 Av. René Cassin, BP 7151, 97715 Saint-Denis, France

Email addresses: christophe.lin-kwong-chon@univ-reunion.fr (Christophe Lin-Kwong-Chon), brigitte.grondin@univ-reunion.fr (Brigitte Grondin-Pérez), amangoua.kadjo@univ-reunion.fr (Jean-Jacques Amangoua Kadjo), cedric.damour@univ-reunion.fr (Cédric Damour), michel. benne@univ-reunion.fr (Michel Benne) membrane or the carbon support [11]. Some others technological locks persist, such as their degradations and failure modes $[12,13]$, prognosis and lifespan [14], corrosion protection [15] and many others. To improved the system reliability one main solution lay in the fault-tolerance control, in order to bring correction to performance degradation and prevent the system to fail [16].

The fuel cell control must considerate its State Of Health (SOH) [17]. For this purpose, two main ways are available [18]. Firstly, through the use of control tools incorporating knowledge of degrading health conditions that needed to be compensated, named Passive Fault-Tolerant Control (PFTC) [19-22]. PFTC is able to take the necessary actions to maintain the control performance, whatever the change of state of the system. This ability to be robust is severely restricted to knowledge brought to the controller. Secondly, through the development of an Active FTC (AFTC) strategy [19, 23-25]. An AFTC includes a diagnostic tool able to determine the system $\mathrm{SOH}$, a decision process to find a fault strategy mitigation and a controller to maintain the control performance. Strong cause and effect relationships exist between the input variables and events of PEMFC systems [24], the change of one input has direct or indirect consequences. For example, the temperature naturally affects water evaporation [26], ohmic membrane resistance, water transport, condensation in flow channels [27], cell performance [28]. Gas flow rates affect the amount of reactant gases, but also water ejection if it is sufficiently high, water accumulation if it is too low [29], slug formation [30], membrane humidity [31] and cell performance [32]. Certain events are at 
the origin of more or less important fuel cell fault that can be reversible, partially reversible or even irreversible degradation. This naturally leads to the development of adaptive strategies allowing, as the name indicates, to real time adaptive control and leading to better performance [33].

Neural Networks (NNs) are well known for their approximation capacity and are widespread in literature through research, such as modeling applications [34-37], speech recognition [38], control [39-43], etc. Neural network models have proven their compatibility with the control domain and their better performance compared to other methods, such as Proportional Integral Derivative (PID) controller [44-46], fuzzy logic controller [47], or sliding-mode controller [48]. Historically, it exists a close connection between machine learning, artificial neural network and control [49]. Indeed, learning methods trace its origins to some techniques in linear systems theory. Learning algorithms increase the intelligence of control and create various autonomous systems. A significant amount of research has been conducted on the adaptive neural control [23, 39, 50, 50-77]. Moreover, thanks to recent years of technological advances, significant progress allows neural machine learning to enjoy a particular international notoriety with the use of deep learning and reinforcement learning approaches [78-82], offering new creative tools in control design [83, 84]. Recently, several reviews about adaptive neural control have been conducted. Jiang et al. [85] have devoted a paper about summarizing recent progress on neural network learning and control for robot applications. Yousefian et al. [86] have proposed a review on machine learning control for power system rotor angle.

This paper provides a review of recent years Adaptive Neural Control (ANC) applied to PEMFC. The study was conducted by a classification of control structures in order to determinate which one is more appropriate according to the fault type and the command variables. Several gaps exist and need to be identified. In order to reduce them, an extended scoping research in systems, such as other fuel cell types, mechanical actuators, chemical and biological reactions, vehicles and photovoltaic systems will allow to take knowledge of the current techniques and to bring an enrichment to PEMFC control.

The remainder of this paper is organized as follows. Section 2 briefly introduce the PEMFC operation, its various health states, and the control needs. Section 3 presents some NN models with classical learning techniques. Section 4 gives the structures relative to adaptive neural control applied for PEMFC. The investigation starts with the direct NN approach, then with dynamic programming strategy, and ends with dynamic equation-based NN control. Articles about PEMFC neural control design covered in this review are detailed in the Appendix A and a summary of article results is completed in the Appendix B. A discussion about the analysis of actual and gap research on PEMFC ANC is given in Section 5. Finally, Section 6 provides the conclusion.

\section{Nomenclature - Abbreviations}

$\begin{array}{ll}A E & \text { Absolute Error } \\ A F T C & \text { Active Fault-Tolerant Control } \\ B P & \text { Back Propagation } \\ E S N & \text { Echo State Networks } \\ G D & \text { Gradient Descent } \\ G D L & \text { Gas Diffusion Layer } \\ I I R & \text { Infinite Impulse Response } \\ I T A E & \text { Integral of Time-weighted Absolute Error } \\ L S & \text { Least Square } \\ M E A & \text { Membrane Electrode Assembly } \\ M L & \text { Multi-Layer } \\ N N & \text { Neural Network } \\ P I & \text { Proportional Integral } \\ P I D & \text { Proportional Integral Derivative } \\ P T F C & \text { Passive Fault-Tolerant Control } \\ R B F & \text { Radial Basis Function } \\ R E & \text { Relative Error } \\ S O H & \text { State Of Health }\end{array}$

\section{PEMFC system}

Fuel cells can be grouped considering the electrolyte that is employed. PEMFC systems use a thin proton conductive polymer membrane $(\leq 50 \mu m)$ [87]. The operating temperature is also specific to each FC type. This study concerns systems that nominally work in a low temperature range between 50 and $100^{\circ} \mathrm{C}$ [88]. Depending on power demand, MEA is stacked in multiple series [11]. In industry, the mono-cells are a minority compared to stacks, nevertheless they remain useful for the research activities. [89, 90]

\subsection{Working principle}

The most important component is the MEA which consists in an electrolyte membrane adjoining on either side by one catalyst layer. The membrane is impermeable to gases, but it conducts protons. In fig. 1 , the incoming hydrogen is oxidized at the anode $\mathrm{H}_{2} \rightarrow 2 \mathrm{H}^{+}+2 e^{-}$, in which it is stripped of its electron. The products of this reaction are hydrogen protons and free electrons, which fill the anodic chamber. Protons travel directly through the hydrated membrane, whereas the electrons travel through electrically conductive collector plates, and passed to an external electrical circuit before continuing to the cathodic chamber. At the cathode, oxygen reaction reduces with hydrogen protons and free electrons $\frac{1}{2} \mathrm{O}_{2}+2 \mathrm{H}^{+}+2 e^{-} \rightarrow \mathrm{H}_{2} \mathrm{O}$. Water is generated as a product, and pushed out of the cell with the excess flow of gas. The operating of PEMFC implies several auxiliaries [87]. There are different modes to ensure pressures, temperature or humidity regulation. One of them is presented in the fig.2, which is composed of five subsystems: a mass flow controller, a thermal system, a humidifier system and a power converter. This configuration offers a simple control and a faster system reaction [91].

\subsection{Operation conditions}

The PEMFC fully exploits its capabilities on an optimal operating point depending on command variables such as temperature, gas pressures, gases flow rates, and inlets gas humidity 


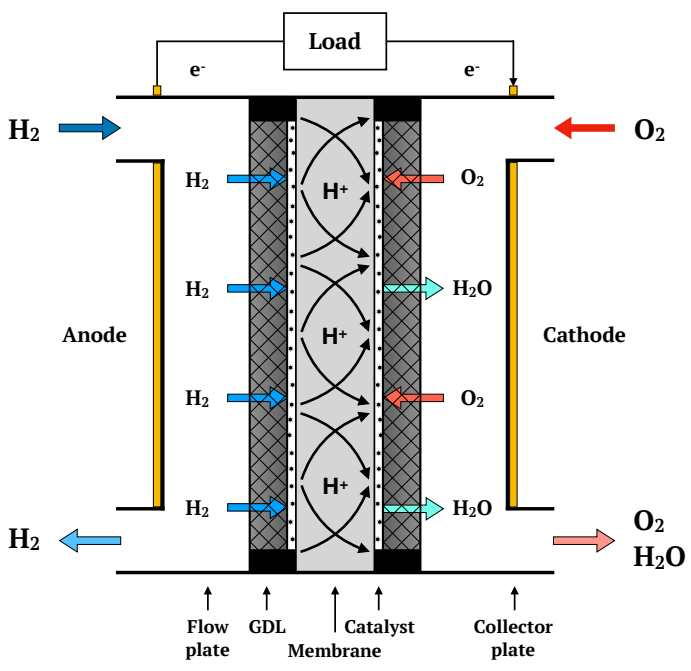

Figure 1: Representation of PEMFC operation.

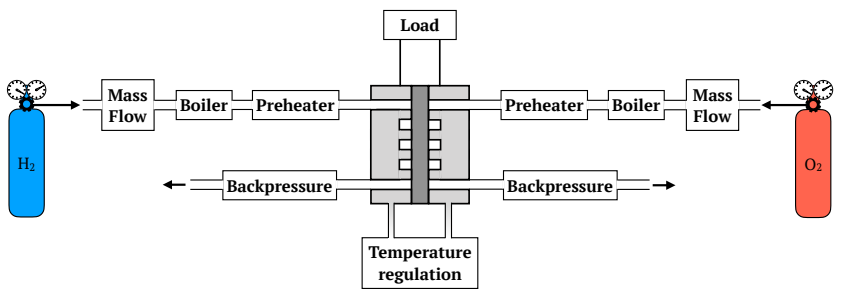

Figure 2: PEMFC auxiliaries.

[92]. The polarization curve characterizes its performance. The change of the operating point ensues the change of system dynamics, which can reduce its efficiency. Typically, this point can be methodologically determined with statistical analysis methods [93] or by neural networks [34, 94]. Not respecting the nominal operating point, depending on commands involved, can lead to the appearance of faults.

\subsection{Performance degradation and failure mode}

Two classes of faults can occur and affect reversibly or irreversibly the PEMFC dynamic operation and performance. Each fault has its own dynamics, and therefore a different response time, ranging from a few microseconds to several days [95]. Thus, the fault dynamics must be taken into account during the design of the controller. Some examples are provided below.

Common reversible faults are related to:

- Reduction of catalyst active sites through obstruction of catalyst layers pores by excess water [95] (response time: $\left.10^{0}-10^{3} s\right)$.

- Poisoning by hydrocarbons as the result of lower purity of reactive gases [96] $\left(10^{1}-10^{5} s\right)$.

Irreversible degradation are related to:

- Corrosion of carbon surface caused by fuel starvation [97] $\left(10^{-3}-10^{1} \mathrm{~s}\right)$.

- Oxidation of catalyst as the result of platinum migration and agglomeration [29] $(<2000 h)$.
- Conductivity loss and creation of pinholes due to the membrane drying out [98] $\left(10^{0}-10^{3} \mathrm{~s}\right)$.

- The presence of cracks or deformation of the membrane [99] that can be caused by excessive differential pressures between anode and cathode, inhomogeneous compression, vibrations, etc.

- Start-stop cycles [100] and extreme environment [101] also promote the reduction of membrane lifetime.

An experimental example of fault influence is given in this paper. Fig. 3 shows the evolution of the polarization curve from a mono-cell that is subjected to cathodic flooding recurrences (from 1 to 10 recurrences). All polarization curves are achieved on the same operating point after each same flooding scenario. The flooding recurrences causes an obvious premature loss of

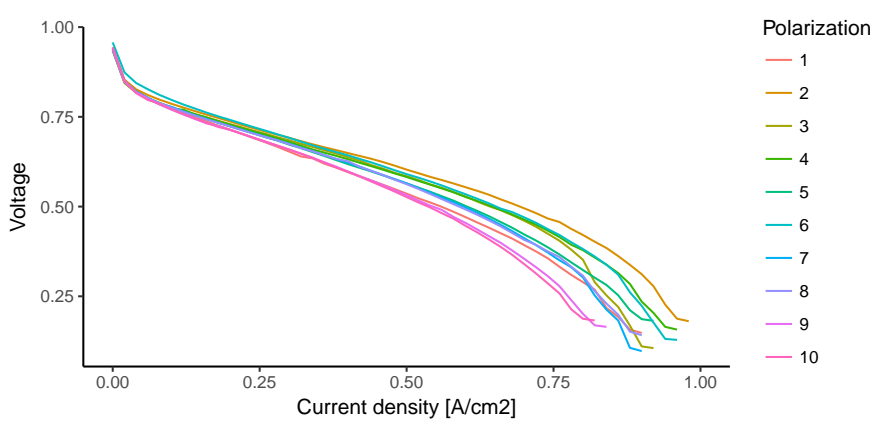

Figure 3: Performance degradation on the polarization curve after several flooding events.

performance, especially the PEMFC ability to hold high currents.

\subsection{Commands variables and control strategies}

One controlled variable can be driven by several command variables, which implies as many actuators. There are 3 main

Table 1: Controlled variables and actuators on PEMFC.

\begin{tabular}{lll}
\hline & Controlled variable & Actuator \\
\hline Fluidic & Stoichiometry $(\lambda)$ & Gas flow controller [33, 74] \\
& & Current load, purge valve [102] \\
& Difference pressure & Pressure regulator [21, 103] \\
Relative humidity & Boiler and pre-heater [104, 105] \\
& & Air blower [106] \\
& & Gas flow controller [107] \\
Thermic & Temperature & Gas electric heater [72] \\
& & Cooling pumps [108] \\
& & Gas flow controller [60] \\
& & Air blower [106] \\
Electric & Power & Pressure regulator [21, 109] \\
& & Backpressure regulator [110]
\end{tabular}

types of controlled variables about the PEMFC, namely fluidic, thermic and electric, all presented in Tab.1. To be efficient in fault mitigation, a controller's response time must be consistent with the response time of the corresponding fault.

The stoichiometry control regulates the ratio of inlet flow rate according to the reacted flow rate. The continuous gas delivery 
is crucial to maintain the stability of electrochemical reactions, either the supply of the electrical load. This prevents global or local starvation that can cause irreversible degradation on the MEA. The action response time must be within a very short time $10^{-3}-10^{1} \mathrm{~s}$, but it will generally be imposed by the gas flow controller settling time $<50-300 \mathrm{~ms}$ [111, 112]. Undershoots in setpoint tracking have directly harmful impact on the MEA's SOH. The adopted controller must allow the minimum of stoichiometry undershoots. The gas flow is also used to evacuate the excess water, in this case the actuator has a response time compatible with the flooding fault $10^{0}-10^{3} \mathrm{~s}$. The same is true for the evacuation of excess heat generated by the PEMFC [106], the thermal response time being more important than the fluidic response time. Faults leading to evolution of system characteristic, performance or behavior, such as channels flooding or actuator faults justifying the use of adaptive control.

The anode/cathode difference pressure control ensures a mechanical equilibrium to the membrane avoiding the deformation and the perforation of it. Here large overshoots, higher than $30 \mathrm{kPa}$ [91], have ruinous consequences on the integrity of the latter. The compressor with a purge valve is a common configuration where the response time of such an actuator is generally less than $1 s$ [113]. To avoid membrane fatigue and wear, the stability of the pressures and thus the stability of the controller should be considered. For power generation, the PEMFC air pressure tracks the required power setting and is therefore subject to the same issue about reactive gas starvation. Pressure controller have typical response time of $<1 s$.

The stack temperature influences the humidification of the reactants and therefore the water content. The control of this variable is commonly carried out via the cooling flow rate. Usually, the anode and cathode inlet gas temperatures are regulated to the fuel cell operating temperature by heat exchangers. This to avoid condensation phenomena at the system inlet, and the temperature balance between the incoming gases and the stack. However, compressor operating cycles coupled with the great dynamical nonlinearities of these heat exchangers are legitimate motives for the integration of an adaptive controller [114].

Neural machine learning and adaptive control have a common vision. The capability to adapt itself to changing conditions. The modularity of this tool in this domain brings creativity in the design of autonomous intelligent systems, in particular by its universal approximation capacity and real-time learning ability. Neural networks are particularly suitable for nonlinear control with presence of faults, hence the relevant results present in the literature $[55,65,66,71]$.

\section{Neural modeling and learning algorithms}

This section briefly presents different neural network topologies, learning techniques and stability analysis commonly employed in adaptive control.

\subsection{Different neural network topologies}

\subsubsection{Multi-layer neural network}

The most emblematic neural model is the Multi-Layer (ML) topology with three layers, including one hidden layer, as illustrated in fig.4. Each node is associated with an activation

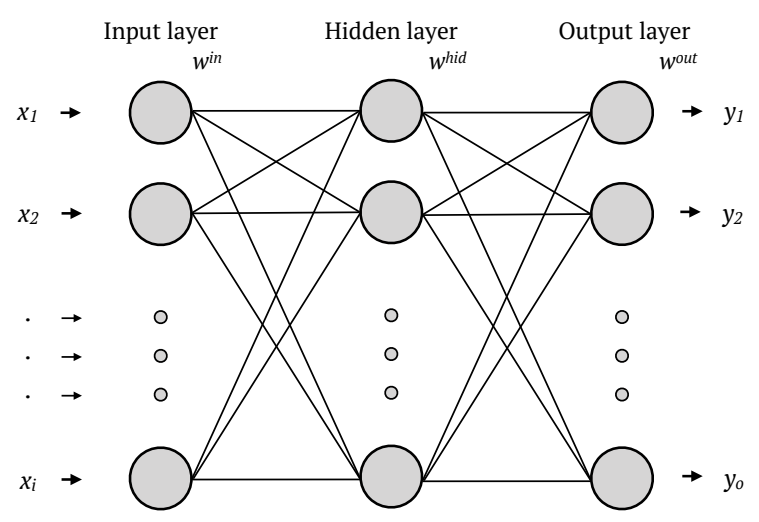

Figure 4: Multi-layer neural network.

function, and each connection possessed a specific weight. A hidden node is computed as follows:

$$
h_{n}^{l}=f\left(\sum_{i=1}^{m} w_{i}^{i n} x_{i}+\text { bias }\right)
$$

where $l$ denotes the number of hidden layers $m$ the number of input nodes and $f$ the activation function. This operation is repeated for $n$ neurons to get the hidden layer computation $h_{n}^{1}:\left(h_{1}^{1}, h_{2}^{1}, \ldots, h_{n}^{1}\right)$. A deep NN structure contains several hidden layers, the first hidden layer computation is then repeated for each of them. Finally, output layer is calculated in the same way:

$$
y_{o}=f\left(\sum_{i=1}^{n} w_{i}^{\text {out }} h_{i}^{l}+\text { bias }\right)
$$

where $o$ is the number of output nodes. All the weights of the layers $\left(w^{\text {in }}, w^{\text {hid }}, w^{\text {out }}\right)$ are elements to be tuned during the socalled training phase.

\subsubsection{Radial Basis Function neural network}

Radial Basis Function (RBF) neural network is commonly used to approximate unknown functions or uncertainties [77, 115-118]. The architecture is similar to a three-layer network. The only difference is its activation function which has Gaussian-like characteristics, the neuron response decreases or increases gradually with distance from a center point. A common form is taken with:

$$
h_{n}(x)=\exp \left(\frac{-\left\|x-c_{n}\right\|^{2}}{b_{n}^{2}}\right)
$$

where $c_{n}$ denotes the $n_{t h}$ center vector and $b_{n}$ denotes the width of the $n_{t h}$ hidden nodes. These two parameters and the weights of the layers are elements to be adjusted. Compared with a ML model, the RBF model generates fewer errors [119] but they suffer from the curse of dimensionality, as the dimension of vector gets high resulting in longer training time. 


\subsubsection{Reservoir Computing}

Two similar independent approaches have been proposed by Jeager et al. [120] and Maass et al. [121], respectively Echo State Networks (ESN) and Liquid State Machines, both based on two basic ideas that are a fixed recurrent dynamic reservoir of neurons and a training phase that only occurs at the output layer. The ESN model is illustrated in fig.5. These approaches

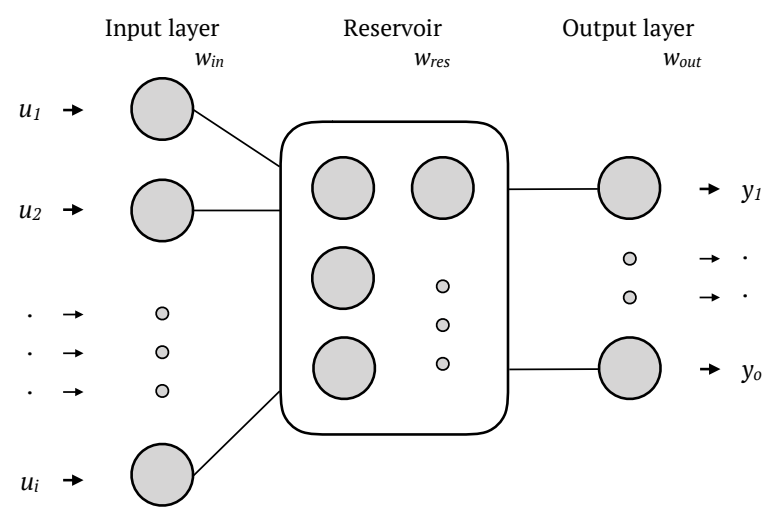

Figure 5: Echo State Networks.

imply memory capacity which is computed by the excitation of reservoir units as follows:

$$
\begin{aligned}
& \widetilde{x}(n)=f\left(W^{i n} u(n)+W^{r e s} x(n-1)\right) \\
& x(n)=(1-\alpha) x(n-1)+\alpha \widetilde{x}(n)
\end{aligned}
$$

where $x(n) \in \mathfrak{R}^{n}$ denotes the vector of neurons activation, $\tilde{x}(n) \in \mathfrak{R}^{n}$ denotes its update, $W^{i n} \in \mathfrak{R}^{n \times m}$ denotes the input weights matrix, $W^{\text {res }} \in \mathfrak{R}^{n \times n}$ denotes the reservoir weights matrix, $0<\alpha \leq 1$ denotes the leaking rate, a memory term. Then, the output is calculated by:

$$
y_{o}(n)=W^{o u t}\left(u_{i}(n), x(n)\right)
$$

where $W^{\text {out }} \in \mathfrak{R}^{o \times(m+n+o)}$ denotes the output weight matrix. Reservoir computing models are well known to have superior performance in time series prediction [122-126] than traditional neural network models. The training phase is performed only on the output layer, which reduces the time and computational loads. The main difficulty with this type of model is the optimization of its hyper-parameters.

\subsection{Optimization for parameters and hyper-parameters}

Model global parameters are related to two groups, hyperparameters and parameters. The hyper-parameters correspond to model structure, such as the number of hidden layers, the number of neurons, the choice of the activation function, the memory term, etc. Recently presented in [127], a solution to automatically find the adequate number of neurons is based on an online incrementation of the neuron number in the hidden layer until to meet the expected performance. In the case of a large number of neurons, an effective dimensionally reduction was proposed in this recent patent [128] with transformed methods such as principal components analysis, random projections or linear reconstruction.
Parameters denote to neural weights or coefficients that are automatically obtained by learning algorithms. Four learning algorithms emerge from research reading about PEMFC, all based on the computation of a cost function. Usually it takes a quadratic form, also known as the Mean Square Error:

$$
J=\frac{1}{2} \sum_{i}^{m}(\operatorname{target}(i)-\operatorname{output}(i))^{2}
$$

\subsubsection{Gradient descent}

Gradient Descent (GD) is a first-order iterative minimization method. Following step by step a negative gradient, the algorithm allows to find an optimal point, which can be a global or local minimum. The adaptation law of neural weights follows this:

$$
\begin{aligned}
& w_{\text {new }}=w_{\text {old }}+\Delta w \\
& \Delta w_{h}=-\eta \frac{\partial J}{\partial w_{h}}
\end{aligned}
$$

where $\eta$ denotes a learning rate that manages the adaptation amplitude. Back Propagation (BP) is a common technique that used GD method to adjust one by one each layer of a ML model. Based on two actions, a forward pass tests the model, and a back pass adapts layers weights.

\subsubsection{Least-square}

Least Square (LS) is an approach of linear regression, where the objective is to minimize the error. In an ideal situation, with perfect neural weights, the outputs are obtained as follows:

$$
Y^{\text {target }}=W^{\text {out }} X
$$

where $Y^{\text {target }}=\left[y_{1}, y_{2}, \ldots, y_{m}\right] \in \mathfrak{R}^{m \times o}$ denotes the desired outputs and $X=\left[x_{1}, x_{2}, \ldots, x_{n}\right] \in \mathfrak{R}^{n \times m}$ is the outputs of the previous layer. In practice, the best solution can be obtained by solving the quadratic problem:

$$
\widehat{W}^{\text {out }}=\arg \min S(W)
$$

where $S(W)=\|Y-X W\|^{2}$ denotes the objective function. Then, new weights are obtained by the resolution of the normal equation:

$$
\widehat{W}^{\text {out }}=Y^{\text {target }} X^{T}\left(X X^{T}\right)^{-1}
$$

where $X^{T}$ is the transpose of $X$. The method is particularly appropriate for ESN model where only one layer is adjusted $W^{\text {out }}[129]$.

\subsubsection{Differential evolution}

The differential evolution approach is based on an iterative search of a candidate solution, here represented by $W$ within a population $P_{g}$ where $g$ denotes the stage of a generation. Evolutionary method is based on principles of mutation, selection and generation [130]. In an area of possible solutions, several candidates are initialized and randomly positioned as $P_{g}=$ $\left(W_{1, g}, W_{2, g}, \ldots, W_{i, g}\right)$, where $i$ denotes the index of the population. Each candidate is evaluated and only the best applicants are selected. A mutation and crossover are processed on selected applicants to obtain a new population $P_{g+1}$. The iteration 
is repeated until the satisfaction of the cost function. Considering the random nature of the algorithm, differential evolution does not guarantee the best result, but allows to cover a larger domain and the tests of unexpected combinations. The main advantages are the no restriction on the regularization methods [131], and the possibility to obtain better performance with a same comparable computation time than traditional methods [132].

\subsubsection{Reinforcement learning}

Reinforcement learning, within the class of actor-critic method, is a learning algorithm that works directly on the policies. It is an intentional way to guide the learning process towards a better performance depending on the benefit of the action taken, whether positive or not. A class of discrete-time nonlinear systems and its associated cost function can be described respectively by:

$$
\begin{aligned}
& x(k+1)=F(x(k), u(k)) \\
& J(x(k), u(k))=\sum_{k=1}^{\alpha} \gamma^{i-k} U(x(k), u(k))
\end{aligned}
$$

where $x(k)$ is the state vector, $u(k)$ is the control vector, $F$ is a nonlinear function, $U(x(k), u(k))$ is called the utility function (7) and $0<\gamma \leq 1$ is the discount factor. Eq. (13) is equivalent to:

$$
J(x(k), u(k))=U(x(k), u(k))+\gamma J(x(k+1), u(k+1))
$$

The process is mainly based on the search of solutions of Hamilton-Jacobi-Bellman equation by an optimization method [64]. According to Bellman, an optimal control signal $u^{*}(k)$ that minimizes cost function $J$ is expressed by:

$$
u(k)=\operatorname{argmin}(J(x(k), u(k))
$$

In control design, two neural networks are regularly designed for approximating the cost and optimal control functions. The optimization problem is regularly solved by the GD method.

\subsection{Stability and convergence in NN control}

Stability and convergence are paramount criteria in controller design, even more, true for NN design in closed-loop control. The validity of model or controller is commonly derived under the assumption that states $x(t)$ remains in some compact set $\Omega$, only ensuring a local stable. Conventional methods, such as gradient techniques do not guarantee system stability and result in problems as overtraining, local minimum trapping, slow convergence or bad transient behavior [133]. That is why, research must provide proofs of rigorous global stability, convergence analysis and repeatable design techniques [134].

A common analysis requires the use of the Lyapunov method. The stability proof of a controller is directly obtained in three steps $[135,136]$, first a derivative of the tracking error equation, second the selection of a proper Lyapunov function, and third its derivation. The equilibrium of time-varying systems is asymptotically stable if the derivative of the Lyapunov function is negative along the target trajectory.
Another method based on a Lyapunov function is performed in [137], which applied the theorem on the discrete-time dynamics NN equations with continuous states. The resulting stability is described by several conditions, including the existence of the positive diagonal solutions of the Lyapunov equations in the discrete-time domains.

In [138, 139], a modified BP algorithm imposing the derived stability condition is used to adjust the NN weights of the controller. The stability is achieved by the proof of the negative derivative Lyapunov function with the linearization neural controller and its control law.

In a recurrent neural network, such as ESN that possesses memory capacity, a large information capability involves a stable equilibrium state. It must ensure that the effect of initial conditions could vanish as time passes. The global asymptotic stability of neural networks implies the Schur stability of the synaptic weight's matrix [140]. The $W$ matrix is called stable Schur diagonally if there exists a definite positive symmetric matrix $P>0$ such that $W^{T} P W-P$ is negative definite.

Small variations or corrupted data in the input of neural models, especially deep networks, may cause significant instability. In order to force the model to deliver the same output for healthy and perturbed inputs [141], a method consists to incorporate small variations directly in the training phase.

\section{Adaptive neural control for PEMFC}

This section presents the content of the scoping review. Several adaptive neural control structures employed in PEMFC are presented and the performances are identified. Throughout the articles, comparisons are made with the PEMFC needs of the section 2, and a bibliographic investigation about other systems informs technological advances and provides perspectives.

\subsection{Neural feed-forward control}

The inverse neural controller is a feed-forward structure that requires no knowledge of the studied system. As shown in fig.6, the aim is to identify an output-input model of a system and make an inversion. One prior condition is to ensure the reversibility of the system. This step is regularly omitted, but some recent publications continue to include it. Such as [142] that used reversibility derivation to prove the existence of the inverse neural network controller for active car suspension control. For PEMFC system, a study has been conducted on the inversion-model based principle [143] which naturally guarantees the reversibility of the relations between commands and variables. The performance of an inverse controller depends directly on the database and the state of the system when acquiring data, thus limiting the validity of control into a predefined operating range. Adding an adaptive feature could extend this validity range.

To prevent oxygen starvation, Li et al. [39] propose a stoichiometry control via the compressor voltage. The controller is a recurrent fuzzy NN. The fuzzy logic method offers the ability of dealing with issues such as reasoning on a higher level. Feedback connections are added in its structure to provide memory 


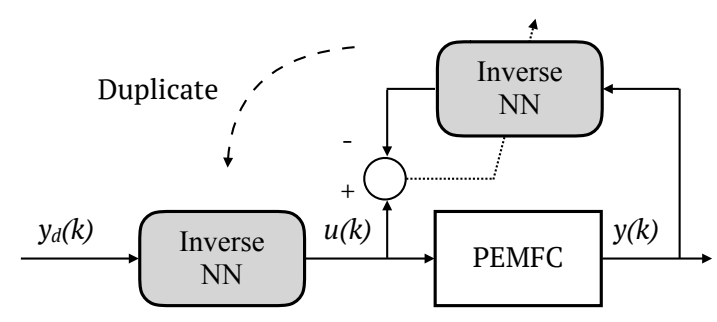

Figure 6: Neural feed-forward controller.

capacity, expanding the ability of capturing dynamic response. Fuzzy learning rates and neural weights are adjusted by a GD method. Simulation results show good robustness to abrupt external current load disturbances, and performs much better compared to the Proportional Integral (PI) controller. The cathode pressure is tightly tracked by the anode pressure ensuring physical integrity for the membrane. Four steps of current disturbances $0.1-0.3 \mathrm{~A} / \mathrm{cm}^{2}$ are tested and some undershoots are visible $0.4-0.1 \lambda_{O_{2}}$ with transient times of up to 10 seconds. The method is interesting for maintaining anode/cathode difference pressure but has significant response times for stoichiometry control.

Sedighizadeh and Rezazadeh [50] proposed to regulate the output power of a $1 \mathrm{~kW}$ PEMFC by changing the hydrogen humidity. This article develops a wavelet $\mathrm{NN}$ with a local infinite impulse response (IIR) block in series to estimate the system output. The wavelet $\mathrm{NN}$ is similar to a RBF model with wavelet transform embedded in the hidden units. In the wavelet concept, a super wavelet is a linear combination of daughter wavelets. This feature allows the wavelet shaping to identify complex nonlinear system. A set of 8 Morlet type wavelet is used in this study. The IIR block creates a double local network architecture, providing a fast learning and convergence of the model. The IIR coefficients are fixed and the neural weights are adapted by LS method. The trajectory tracking is effective, the presence of overshoots and oscillations is probably related to the choice of the control variable.

Instead of using a single duplicate $\mathrm{NN}$ model, another method used two separate models. For nonlinear systems with high uncertainties, Shafiq [51] recently proposed a direct inverse controller based on two different ML models. A first ML is used to estimate the system model and generate an estimation of the system output. The error output is used to adjust the weights of the ML controller using a BP algorithm. Then, the output of this first model is used as a residual error for the second model. This configuration gives robustness properties against disturbances and model mismatches. Simulation results show a good performance, smooth tracking, stabilization, and a good disturbance rejection on one Hammerstein system. A mathematical model that can be able to describe many chemical and other industrial processes. The controller reaches a very small convergence time $0.15 s$ in this application. On the other hand, this method presents a strong overshoot at the first moment. Stability and convergence of the controller are separately covered by authors in a subsequent article [144]. The convergence of the error to zero and the boundedness of the controller parameters are provided with the Schur stability verification of polynomial theorem.

A solution that presents few overshoots have been recently developed by Jordanou et al. [52]. It consists in control of a bottom-hole pressure for an oil well with one direct ESN model. The control objectives are pressure setpoint tracking and disturbance rejection. An ESN-learning is adjusted with a recursive LS method, then the output layer is duplicated into an ESNcontroller. The LS method avoids the problem of local minima. Simulation results show the capability to cope with larger changes of pressure and the good disturbance rejection. Simulation results show the tracking capability with no oscillations or larger overshoots. It is noted, however, that five random trials were needed to find working initials neural weights.

As seen above, the inverse neural structure is particularly suited for control of nonlinear system with uncertainties. However, the method has large command signals and has rather high response times. Thanks to the use of advanced neural models, some works have been done to reduce overshoot, while increasing the robustness against disturbances. For example, presented here, the least-squares based learning methods for the tracking capability, or the addition of a second NN model for the anticipation action to reduce the controller convergence time.

\subsection{Neural hybrid feedback feed-forward control}

The combination of the inverse neural control with a feedback controller brings a second support yielding a more advanced control. As shown in Fig.7, the feed-forward controller extends its bandwidth for steady state disturbances [145], while the feedback control reduces the residual error, ensuring compensation for disturbances and modeling errors.

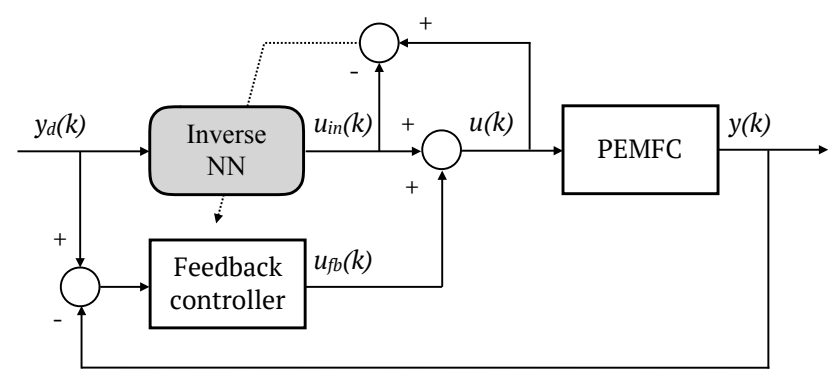

Figure 7: Neural hybrid feedback feed-forward controller.

Rakhtala et al. [53] developed a combination of inverse ML model and a PID controller for a 6kW PEMFC voltage control via the inlet air pressure. The control objective is to improve stability and reduce transient time of current changes in order to limit the membrane degradation. The learning algorithm is based on a GD method. Simulation results show fewer fluctuations in the transient response of the voltage. Compared to a PID controller, the proposed method allows a smoother air pressure. Voltage overshoots with an intensity of $0.03 \mathrm{~V} /$ cell are present for a setpoint of $0.87 \mathrm{~V} / \mathrm{cell}$.

Rezazadeh et al. [54] presented a methane flow control for a $5 \mathrm{~kW}$ PEMFC. The controller is based on an inverse RBF neural network and a PID to generate the command signal. Stability 
is ensured using the Lyapunov theory and RBF weights are adjusted with an adaptation law. Simulation results show an acceptable robustness with variance of $1 \%$ in the presence of an additive load current noise with a standard deviation of $0.2 \%$.

A situation of auxiliary degradation was achieved in the same year by Ragb et al. [55] for oxygen stoichiometry control via the compressor voltage. The controller is designed with the same structure, a RBF neural network and a PID controller. When a residual error occurs, the PID controller output increases. That is when neural weights must be adapted, it is achieved at each sample time by a recursive training algorithm based LS method. The validation of the adaptive controller is realized with a situation of loss compressor gain $30 \%$ and time varying currents. Simulation results show the ability of the proposed controller to provide approximately the same performance for a healthy system and a faulty condition. Some overshoots are noticed $0.2-0.8 \lambda_{\mathrm{O}_{2}}$ for an oxygen stoichiometry setpoint of $2 \lambda_{O_{2}}$, furthermore, the convergence time is accomplished in a few seconds.

The previous articles highlight the contribution of smoothness in trajectory tracking and command variables, improving system stability. Recently, the same structure was used for the angular control of a pneumatic artificial muscle actuator. Son et al. [56] have implemented an inverse nonlinear auto-regressive network with exogenous inputs NN with a PID controller. Neural weights are offline trained with a modified differential evolution algorithm and online adjusted following a fuzzy logic method. This offline training is a promising globally stochastic optimization method with advantages as simplicity and better performance. The major disadvantage is the slow convergence time, that is why it is offline computed. When an error appears, the PID controller generates a command that is compared to the neural command. The residual and its derivative are encircled by several levels of intensity, and in accordance with fuzzy logic method, for each a learning rate would be associated. Thus, neural weights are more or less adjusted, or not at all. The proposed method rejects the steady state error, and obtains better adaptability and precision.

The hybrid NN controllers provide effective performances on the PEMFC. Nevertheless, in this structure, the use of a fixed traditional controller can acts as a passive FTC. It limits the control to a specific system state, and it will not be aware of others system states, such as faulty or degraded states. Recent work has shown a real interest in improving accuracy and adaptability of this control structure.

\subsection{Neural feedback control}

The feedback neural-based model possesses the residual error signal that modifies its function of inverse dynamics into a pure controller. As can see in Fig.8, the learning phase of this structure is generally reached online, therefore, a learning period is necessary during which the controller performance refines gradually.

Sanchez et al. [57, 58] worked on an air stoichiometry control for a PEMFC using a B-Spline neural network [146]. The main advantage of this kind of model is its smoothness output that is due to the basis functions. B-Spline technique is

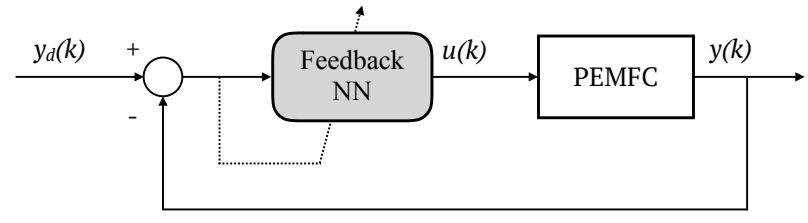

Figure 8: Neural feedback controller.

based on a data transformation by the application of several basis smoothly functions before the computation of input data into neuron layers. The input vector becomes sparse, information is stocked locally following the weighting of basis functions. Therefore, only a few numbers of basis functions participate in the controller output thus reducing the computational effort and time execution. Neural weights are estimated online using an instantaneous rule based GD method. Simulation results show, under load current steps, fewer oscillations and overshoot reduction on the compressor voltage with the proposed adaptive approach than a fixed PI controller. In addition, the neural controller reaches a convergence time of $1.4 \mathrm{~s}$, which is interesting for fault mitigation, such as flooding or dying out. Some overshoots are still present, with a maximum of $0.7 \lambda_{O_{2}}$ for an oxygen stoichiometry setpoint of $2 \lambda_{O_{2}}$.

Dong et al. [59] presented a PEMFC temperature control via the hydrogen, oxygen and water cooling flow rates. The effect of these flow rates is different from each other, this is why a divided-area control is established. For a maximum error of $4{ }^{\circ} \mathrm{C}$, the control variables are the gas flow rates. For a larger error, the control variable becomes the water cooling flow rate. The activation functions of the NN are fuzzy logic type. The Sugeno fuzzy logic system is applied to the identification of the controller. The 5-layers NN coefficients are adapted by a BP method. The controller is tested with a start-up condition to regulate the temperature rise from $50{ }^{\circ} \mathrm{C}$ to $80{ }^{\circ} \mathrm{C}$, and $50{ }^{\circ} \mathrm{C}$ to $100{ }^{\circ} \mathrm{C}$. The simulation results show very smooth flow rates control and few fluctuations over the transition period.

Another article works on temperature regulation. Tao et al. [60] designed a learning fuzzy neural network to maintain the PEMFC temperature via the gas flow rate. The neuron-fuzzy controller regulates the anode and cathode flows to regulate temperature of the stack. The control of temperature via the gas flow has consequences on the flow rates of reactant gases. But the influence is small here with systems using low flow configurations. Two fuzzy NN models are used, the first is to identification model and the second is a multi output feedback controller. The controller is adjusted by a BP algorithm and based on the residual temperature error. The proposed method is tested in a start-up simulation and reached the desired temperature $80{ }^{\circ} \mathrm{C}$ smoothly and rapidly, in addition, fluctuations are also low.

Another way for neural adapting is based on the Jacobian information, the sensitivity of the system output to each control input $\partial y / \partial u$. Shirzadeh et al. [61] proposed a control for a quadrotor type aerial robot that is in pursuit of a mov- 
ing target. One feed-forward model is used for identification of the Jacobian information and the second model is designed for the generation of the control signal. Neural identifier weights are adapted following the residual error, and neural controller weights are adapted following the Jacobian information. Convergence of the neural network identifier and controller is ensured by a proper selection of the learning rate. In spite of the presence of disturbing forces and torque, simulation results displayed a good performance.

More recently, a combination of feedback neural model with a compensator controller was investigated by Jon et al. [62] for a tracking control of senseless permanent magnet synchronous motor servo drive. In this case, neural weights and learning rate are adjusted online by adaptive laws-based GD method and derived from Lyapunov theorem to ensure the stability and the convergence of the controller. Simulation results show a convergence speed greater than a PID controller 150 to $40 \mathrm{~ms}$ and the suppression of transient vibration. In this article, the proper selection of learning rate ensures an optimal compromise between convergence speed and instability.

Adaptability and convergence time are the main assets of this control structure, thus limiting oscillations during transient phases. For the air supply control, the fast convergence time of the neural feedback controller allows further control research under flooding or drying out faults. Just as the inverse controller, stability must be ensured as it is done in literature. Inevitably a proper selection of the learning rate is a key to improve control performances.

\subsection{Dynamic Programming}

Dynamic programming is an algorithmic method to solving optimization and optimal control. The method is based on the concept of reward and punishment (13) to iteratively compute the optimal policy. An actor model is in charge to deliver the correct policy while a critic model evaluates a cost function and adapts the actor model. Revealing in these recent years, the combination of dynamic programming, neural networks and reinforcement learning $[147,148]$ offers many tools for approximation of the critic and action functions [149].

Almeida et al. [63] proposed an optimal PEMFC voltage control via the gas pressure. The control is based on the parametric cerebellar model arithmetic computer NN. This neural network has three layers: a fuzzy input layer, an internal long memory layer represented by parametric equations and an output short-memory layer. A solution to avoid local minimum is composed of two parts. A first offline training is based on a PID controller that initialized the long-term weights, which are the coefficients of parametric equations. Then, the online adaptation occurs only on short-term weights, which are output weights. Two NNs are used in the control structure, an identification NN and a NN controller. The involved structure is based on the neural optimal control method that is roughly similar as a simplified dynamic programming method without a critic neural model, which is substituted by a cost function. Output system is affected by some immeasurable uncertainties, which represent temperature variation, actuators and sensor nonlinearities. A healthy reference model is implemented to be compared with the system output. This residual error and the identification NN output are used to compute the cost criterion. Then, this performance will adjust controller weights with a GD method. The proposed controller is compared to PID controllers under changes of current. Simulation results show a clear advantage of the proposed algorithm, better accuracy with a mean square error from 0.99 to 0.24 and four times smaller variations on gas pressure command. The main advantage is the automated tuning phase through the minimization of the cost criterion function.

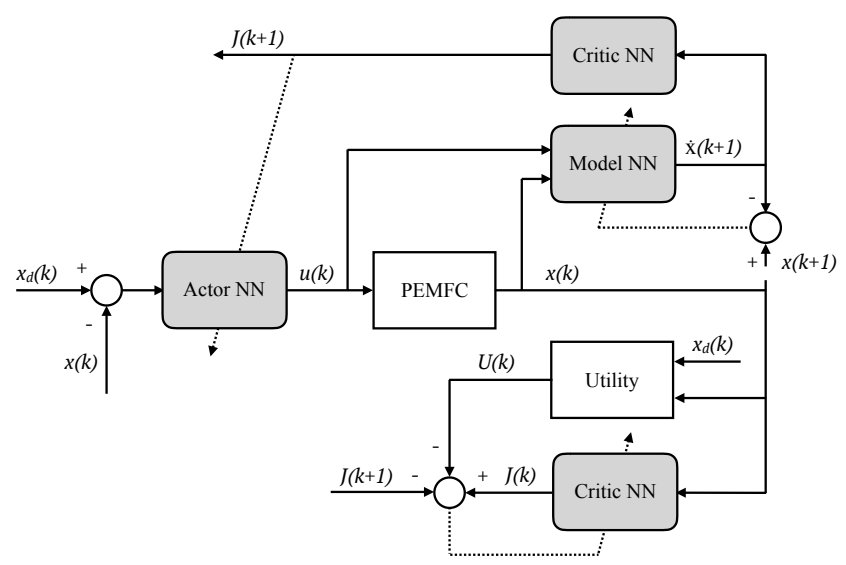

Figure 9: Adaptive dynamic programming controller.

With the aim of anticipating consequences of the actions taken by the actor module, a prediction module could be envisaged in the control design. Bo et al. [64] lately proposed a control for an application of dissolved oxygen concentration in wastewater treatment process. The method used belongs to the heuristic dynamic programming class. Organic matter degradation is strongly nonlinear with large uncertainties, time varying parameters and significant environment perturbations. The control structure is based on three ESN models that are Critic ESN, Actor ESN and Predict ESN. The algorithm of ADP shown in fig.9 is described by seven steps:

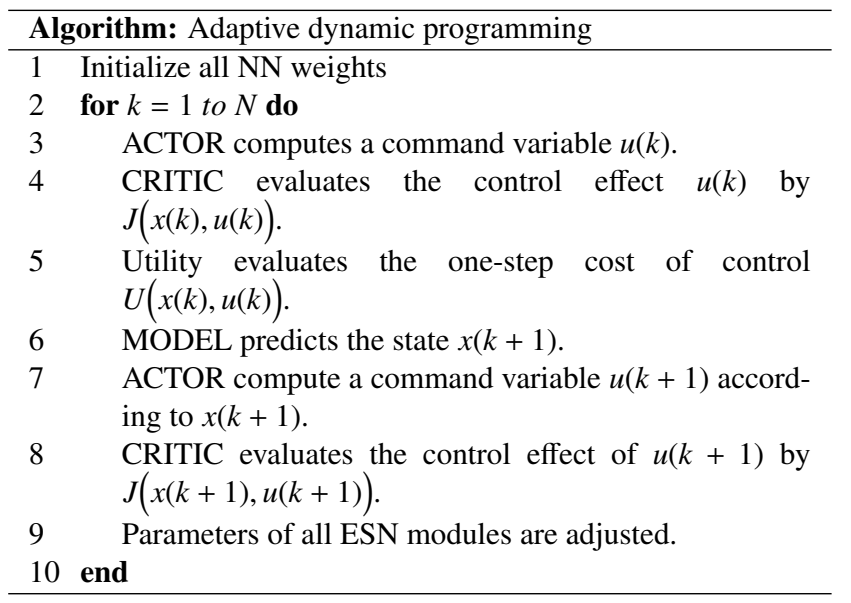

ESN weights are online adjusted with a derivation of LS method. At the startup of the control, a time of adaptation is 
necessary. After a while, the weights of ESNs stabilize and the residual error of the cost function gradually decreases even in the presence of rain or stormy weather. A comparison with PID controller is achieved. Simulation results show a smoother control and smaller deviation. Under interference environment, overshoots and adaptability of the proposed controller are better than a PID controller. Adjusting time is also shorter, from 0.65 days for a PID controller to 0.45 days for the proposed controller.

In recent years, dynamic programming methods based on deep NN model have emerged that can offer better learning and faster convergence [150]. The dynamic programming controller offers a great versatility, flexibility, and operational robustness. However, it requires an important computational effort. Moreover, this control structure requires a stable state of the system to be initialized, which could be a brake to control integration. The dual dynamic programming class is one of the solutions to overcome the need to have a stable state when initializing the controller.

\subsection{Proportional Integral Derivative}

The traditional PID controller is without a doubt the most widely used controller in industry [151]. Based on a residual error, a control law (16) delivers a corrective signal to the system. This method requires the adjustment of three parameters: a proportional term $k_{p}$, an integral term $k_{i}$ and a derivative term $k_{d}$. Traditionally, manual trial-error or heuristic method [152] are adopted for tuning PID controller parameters, but these procedures must be repeated for each change of system state. To remedy this situation some self-tuning methods are investigated in the literature [153], such as fuzzy logic method or neural network.

$$
u_{\text {pid }}(t)=k_{p} e(t)+k_{i} \int_{0}^{t} e(\tau) d \tau+k_{d} \frac{d e(t))}{d t}
$$

An approach to adapt the PID controller parameters with the generalized minimum variance NN-based algorithm was performed by Lebreton et al. [65] and Damour et al. [66]. The authors proposed to improve the resilience of PEMFC air feeding by implementing an auto-tuning PID controller. A ML NN is established as a dynamic model of the system and used to predict oxygen stoichiometry. Neural weights are offline trained and fixed. Starting from this neural network, PID coefficients are online determined by two steps. Foremost neural weights are extracted and linearized using the first-Taylor development. Afterward a generalized minimum variance algorithm is used to minimize a goal function in order to determine new PID coefficients. At each sample time, PID parameters are recomputed. The proposed controller is tested under two scenarios, one healthy system and one faulty oxygen flow controller with an offset of $-200 \mathrm{sccm}$. Experimental results show a good performance with the proposed controller compared to a traditional PID controller, maximum relative errors are respectively $+140 \%$ and $+30 \%$. For the adaptive neural PID controller, the global error decreases by $50 \%$ to $20 \%$. During the faulty time and under disturbances, a constant error is presented with the traditional PID controller $15 \%$, which is not the case with the proposed controller. A reduction of overshoots is noticeable for an oxygen stoichiometry set up at $5 \lambda_{O_{2}}$, from $2 \lambda_{O_{2}}$ for a PID controller to $1 \lambda_{\mathrm{O}_{2}}$ for the proposed controller. Nevertheless, under the healthy scenario, the PID controller is more responsive and converges faster.

In this other article [23], authors combined this control method with an AFTC strategy, including neural model-based fault diagnosis and a reconfiguration mechanism. Voltage and cathode difference pressure of the PEMFC system are compared with a healthy ML network. According to several error thresholds, fixed by experience, the diagnosis of flooding or membrane drying out fault is given. Next, a switch is used to change the desired output for the self-tuning PID controller following predefined values.

The Jacobian information is also used to adapt PID parameters. Recently, Xu et al. [67] used a constrained self-tuning PID based on a RBF for a solid oxide fuel cell control. The control is oriented on fuel flow to improve control performance face time-varying characteristics. The RBF is used to estimate the Jacobian information, while PID parameters are adjusted with a GD method. Comparison with a PID controller shows fewer overshoots under change of current load, but brings small oscillations in transitional periods.

Another means of adaptation is directly based on system variations. Sedighizadeh and Rezazadeh [68] proposed a power control of a $1 \mathrm{~kW}$ PEMFC via the inlet reactants. The authors developed a wavelet-IIR NN model and its output is used to adapt the PI controller. The proposed controller is provided with 57 Morlet wavelets. Under a power variation per unit of $0.8-1$ the proposed controller performs effective trajectory tracking compared to a inverse wavelet NN. Small fluctuations are present in the static period, and the convergence time is a few seconds.

In another articles, the same authors [50] established a PEMFC power control via the hydrogen humidity. The controller is a combination of a wavelet-IIR NN with a PID controller. Here, the NN retains the role of system dynamic estimator. This output is used by adaptive laws GD-based to determinate the PID parameters. Here, the number of Morlet wavelet is fixed as $K=8$ to identify the unknown PEMFC model, this parameter is optimized by trial and error. A test with noise on the output port of the system is performed. The proposed controller demonstrates a robust and fast capacities of trajectory tracking. Some overshoots and oscillations are present on the power signal.

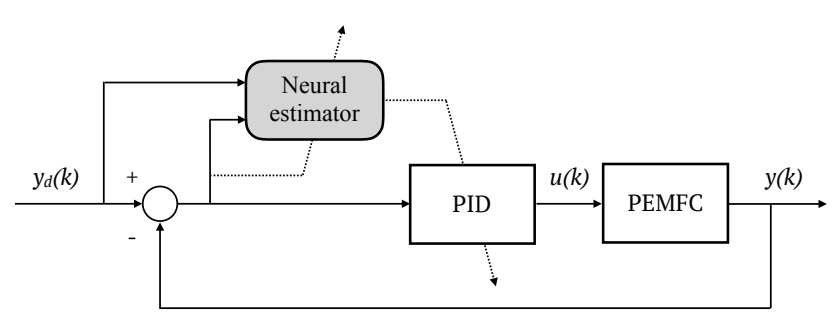

Figure 10: PID. 
As can see in fig.10, PID parameters can also be directly estimated by a neural model. A direct approach was undertaken by Guoai et al. [69] to develop a power control of a 60kW PEMFC via the air pressure. The controller is a self-tuned neural-PID based on Elmann-type NN. Two NNs are implemented into two loops, at time $t$ and $t+1$. The neural identifier is used to predict the future air pressure, and a neural controller is used to estimate the PID parameters. The predicted pressure is used to adapt the neural controller, which allows to anticipate its action and adapt the PID controller. All neural weights are adjusted by BP algorithm. Simulation results show a good adjustment in real time of air pressure following the output power changes. The change is more stable and has a better tracking control effect.

Variations of this control structure exist, in particular those adding constraints on the control signal. For example, Ji et al.[70] recently presented a constraint fuel flow control for a solid oxide fuel cell. The compensator signal essentially deals with control fuel utilization that must be constrained to protect FC components and actuators. All weights of RBF NN are online adapted by GD method. An asymptotic convergence theorem is defined for selecting appropriated learning rate and its proof by a Lyapunov method. Under changes of load current, simulation results achieved good performance.

An interesting hybrid AFTC is recently employed by Huang et al. [71] to control a mars entry via an adaptive RBF neural network. In normal condition, the vehicle is regulated by PID controller, while input commands and system variables are used to train the neural network. A feedback neural network is used to fault detection. When a fault appears, the control is switched from the PID controller to the neural PID controller. As it is difficult to achieve the desired effect under actuator failures when using the traditional PID controller. In this proposed controller, the PID parameters are adjusted directly by the RBF neural network. Convergence and stability of both neural networks are verified and analysis by Lyapunov theory. Simulation results show lower overshoots with the proposed controller.

Neural networks could also directly simulate the PID controller as a PID-like.

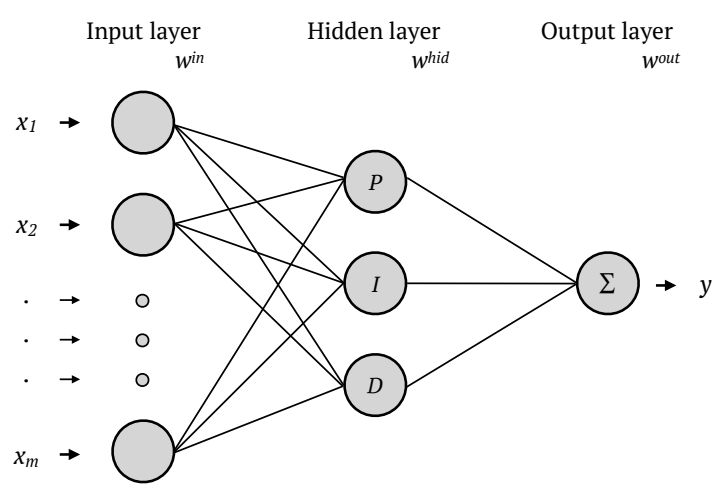

Figure 11: PID-NN with 3 hidden nodes.

As can see in fig.11, this neural structure is a multi-layer with three hidden nodes. Each node corresponds at each PID param- eters with its proper weight. The output layer is composed by a unique summation that directly delivers the control laws. A 12W PEMFC temperature control was achieved by Li et al. [72] with this method. The method is performed on a low-power system. Temperature is controlled by a gas heating resistance. PID parameters vary over time, they are adapted following residual errors via a GD method. Experimental results and a comparison with a PID show less overshoot and a better stability for the proposed controller. However, the temperature converge time is slower and the PID reached the desired temperature 1 minute ahead of time.

One approach allows a compromise between robustness and speed of adaptation. Recently, Zribi et al. [73] proposed the same control method for a thermal nonlinear process with an adaptive momentum tuning method to manage acceleration or slow down the adaptation of PID parameters. In this way, the proposed controller has a better tracking performance.

The PID controller tends to generate oscillations and fluctuations if it is poorly tuned. Presented in previous articles, the adaptive neural PID structure offers a satisfactory performance, a rapid convergence, less overshoot, while remaining simple to implement. It also has the advantage of having been tested on system failure, flooding and drying out faults. The neural model brings a great flexibility to the three parameters, whether they are adapted directly or not. To protect the system, constraint modules can be added while maintaining good performance. The use of Jacobian information with two NN model allows the reduction of overshoots. And a stability analysis, too often omitted, can be undertaken with Lyapunov's theorem.

\subsection{Linearization}

The feedback linearization approach allows to generate a control law from a dynamic model. It requires the existence of characteristic equations and the possibility of quantifying states by means of sensors or estimators. The objective is to linearize the map between input and outputs variables [154], to transform a nonlinear system into an equivalent linear system with the aim of applying linear control techniques. Then, using the nonlinear mapping to transform back to the linear controller into the original space. A complete knowledge of system states is necessary to compute control laws; however, some uncertainties term could be included in dynamic models. To deals with it and provide perfect model matching [136], adaptive laws are designed from error equation to estimate controller uncertain parameters, such as manufacturing variation, temperature distribution [155], disturbances [75], or degradation.

A first approach for maximum power tracking of PEMFC via oxygen stoichiometry was proposed by Zhang et al. [74]. The controller design is based on a hybrid controller between spacestate equations to generate a control law and a ML model to predict the stack voltage. The employed linear model is obtained from linearization of the ninth-order dynamic model [156] and neural weights are adjusted by BP method. Simulation results, under changes of current load, show an accurate and fast response time $1 \mathrm{~s}$. Some overshoots are noticed $0.2-0.5 \lambda_{\mathrm{O}_{2}}$ for a desired stoichiometry of $2 \lambda_{O_{2}}$, but they are small amplitudes. 


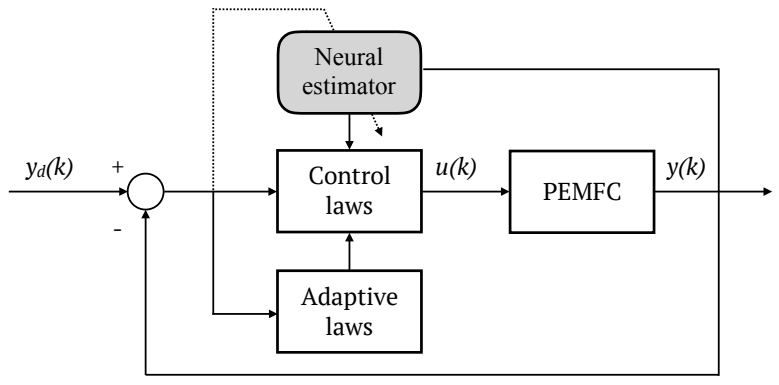

Figure 12: Feedback linearization.

Abbaspour et al. [75] recently developed a control of anodic and cathodic pressures in order to avoid membrane degradation. Some uncertainty parts are unknown in the feedback linearization. To tackle this problem, a ML model is developed to estimate the dynamic model error of PEMFC system. The neural output is a compensation signal for the nonlinearities, such as a disturbance. The proposed controller is tested under load resistance variation and in disturbing scenario. A comparison with a PI controller, under the situation of disturbance rejection, shows a reduction of 2.6 times of oscillations with the proposed method. Moreover, a reduction of the computation time up to $41 \%$ compared to a nonlinear controller. Under uncertainties scenarios and compared to a nonlinear controller, the neural adaptive control demonstrates a decreasing of oscillations for anodic and cathodic pressures, respectively $20 \%$ and $40 \%$. In this last scenario, PI controller demonstrates inability to regulate pressures.

The fuzzy neural model offered a major interest in literature, including overshoots mitigation. Mumtaz et al. [76] lately proposed a maximum power point tracking control for a photovoltaics system consisting on a feedback linearization-based neuro fuzzy controller. The system is in a grid connection with other energy and backup sources, like batteries, electrolyzer, or a $260 \mathrm{~kW}$ fuel cell. To track the maximum power point at all environmental conditions, the fuzzy approach seems an adequate candidate to perform under fluctuations. A six-layered neuro fuzzy identifier is used to estimate unknown nonlinear functions of the state vector, while its parameters are adjusted by GD method. The proposed controller is compared to several incremental conductance methods based on adaptive direct/indirect neuro fuzzy, and adaptive PID controllers. Simulation results show the best performance with the proposed controller, a small steady state error of $2,5 \mathrm{~kW}$ and an undershoot of $1 \%$, while other controllers reach errors of $19.7-105 \mathrm{~kW}$ and undershoots of $5-60 \%$.

The state-feedback linearization controller equipped with sensors is a powerful control tool, but requires a greater financial cost. In return, it offers a better performance. The implementation of neural models allows to deals with complex approximation problems, while being online data-driven updated. With a such controller, weight updating law, stability and convergence of the closed-loop system are rigorously established.
Here, the choice of an advanced neural network, such as a fuzzy network, seems to improve function estimation and helps to reduce the phenomenon of overshoots.

\subsection{Backstepping}

The backstepping design is based on the decomposition principle of a complex system in a succession of reduced one-order subsystems. It associated feedback control laws and Lyapunov functions in a systematic manner. Each degree of the nonlinear model is divided into a cascade closed-loop form, and treated one by one to design pseudo-control laws, named virtual control laws. From the known stable subsystem, a recursive processing stabilizes each other subsystems. Finally, all pseudo-controllers are integrated to retrieve the global control law. As can see in fig.(13), neural models are used for their ability to approximate nonlinear functions, system states that cannot be measured or even unknown variables, which resulting in alleviated control design.

A comparison of backstepping controllers and inverse-based controllers were investigated by Departure et al. [157] for a velocity control of Electric Vehicle powered by a $1.2 \mathrm{~kW}$ fuel cell. The backstepping is established from a second order traction model and the inverse model is deducted from an energetic macroscopic representation. Comparison results show that backstepping admits a lower overshoot during acceleration phases, which ensues to a better tracking performance.

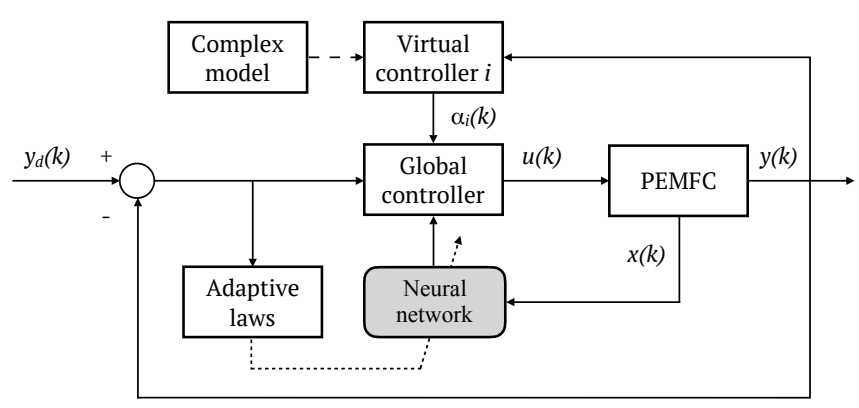

Figure 13: Backstepping.

A work about oxygen excess ratio for a $75 \mathrm{~kW}$ PEMFC was involved by Li et al. [77]. The controller is designed to regulate oxygen stoichiometry via the compressor voltage. First, a Taylor series expansion method is used to transform a nonaffine function into an affine function. Then, the controller is designed using backstepping procedures on the affine model. A dynamic surface technique, which is a linear filter is proposed to avoid the tedious derivatives of the virtual control. Finally, unknown terms are approximated using a RBF with parameters adaptive laws. A theoretical stability analysis is performed to guarantee the final output tracking accuracy and transient performance. Adaptive laws for RBF parameters are updated by dead-zone projection adaptive law, this assures ultimate uniform boundedness. The proposed controller is compared to a feedback controller and a PID controller under a series of step load current. The adaptive controller shows fewer oscillations 
than a PID controller and a better settling time $0.05 s$ than a feedforward $>0.30 \mathrm{~s}$. Overshoot values $0.5 \lambda_{O_{2}}$ are slightly inferior to those obtained with the PID controller.

In literature, this approach is widespread and provides roughly the same performance. The backstepping controller is well suited to the regulation of fuel cell inlet gases, surpassing most conventional methods. The benefits are many, including the global asymptotic stability and the use of a neural model for the state system estimation. The real difficulty lies only in the derivative of virtual control law and the variable changes according to the number of states $n-1$ of the system. The contribution of the neural model as adaptive gain offers a simple solution to estimate immeasurable variables, reduce the chattering phenomenon and increase the control accuracy. Experimentation tests with fault conditions would allow this controller to be tested and its performance to be further evaluated.

\section{Discussion}

A large number of methods are invested and developed in the literature. Among those established to regulate the PEMFC systems some main purpose is identified as follows:

- Stability improvement in the presence of disturbances [54, 75].

- Maintain performance at any set point [50, 57-60, 63, 68, 69,

72, 74, 77].

- Maintain performance in the presence of an auxiliary fault $[55,65,66]$.

- Prevent fault [39, 53].

- Fault mitigation [23].

A wide panel of $\mathrm{NN}$ types and adaptive mechanism are implemented for the PEMFC, allowing a diversity conducive to a discussion.

In summary, significant progress of NN-based controllers have been conducted for PEMFC. Three main control variables emerge from this paper, the mass flow, the pressure and the temperature. The gas flow rate requires a fast action to serve efficiently the amount of reactant. It is a control of stoichiometry gases, which must be a rigorous regulation in order to limit the duration of starvation due to low stoichiometry. The same applies to the excess of water evacuation due to high stoichiometry. The best way to achieve this is the backstepping approach that perform a response time less than one second, while being robust to disturbances limiting the oscillations that can be detrimental to the stability of the system. Neural-PID type controller is also a relevant approach, having already proven themselves in cases of system fault recovery, such as flooding, ordrying out and auxiliary failures, such as compressor or mass flow controller losses. The anode pressure must be controlled following the changes to the cathode pressure to keep null the pressure difference between the membrane sides. An insufficient control generates variation of pressure, which causes mechanical stress on the membrane and instability on output voltage. A study about the presence of unknown disturbances and parameter uncertainties is greatly performed with a feedback neural-linearization approach. It demonstrates the ability to eliminate undershoots and overshoots in normal condition. Effects of disturbance rejection of the controller are illustrated in the online neural adaptation. Indeed, weights converge to zero after disturbances disappeared, thus the neural network perfectly compensates for disturbance. Furthermore, it is observed less errors amplitude and oscillations under the presence of parameter uncertainties. Temperature control is an important aspect in the operation of the fuel cell. Controlling the temperatures of the boilers, the distribution pipes or the stack, ensure a good reaction of the chemical species and management of relative humidity. To the best of authors knowledge, only few adaptive neural approaches have been developed for a dynamic temperature control and precisely on the stack temperature. The neural-PID controller presents the best control tracking for high current with relatively low overshoots. For low currents, the neural-feedback gives a good performance. To improve the performance and adaptability, some future developments can be provided. Firstly, the backstepping controller with neural observer appear as an approach to determine nonmeasurable states, such as uncertainties and faults conditions. Then, an adaptation by fuzzy logic method seems an alternative to dealing with overshoot mitigation and system states consideration. Finally, dynamic programming approach with reinforcement learning could be an interesting line of research, while implementing advanced neural model such as deep structures. Anyhow, these control approaches must retain those primary aims:

- Generation of a command action with a response time in adequacy with nature of the fault. Ensuring a correct convergence and mitigation time.

- Implementation of an actualization mechanism for controller parameters, in online and real-time operation.

- Maintaining stability system even under faulty or disturbance conditions.

Development of control strategies considering explicitly the $\mathrm{SOH}$ of the system appears to be mandatory to extend durability and improve reliability of PEMFC systems. After a great deal of separately works on diagnosis, decision and control, future works should be developed under interactive association between these modules and focus on AFTC strategies. Indeed, experimental validations are few and limited to only faults of flooding, membrane drying out and system failure. This is mainly due to the difficulty of setting up other faults, whether in simulation or experimental.

\section{Conclusion}

In this paper, a detailed review about adaptive neural control is carried out on the proton exchange membrane fuel cell system. This study outlined some relevant controllers for each main regulation variables, such as the backstepping controller for flow rate, the feedback-linearization neural-based controller for pressure and the neural-proportional integral derivative controller for the temperature. These control structures offered good performance compared to others controller, which constantly ensures to maintain optimal operation under tracking 
trajectory, presence of external disturbances or existence of auxiliary failure. Nevertheless, few of them are tested under conditions of system faults, which are still main responsible for performance degradation and lifespan reduction. Moreover, they can be further improved with the aim to implement a real-time regulation. Some emerging topics, such as the use of advanced neural networks, implementation of neural network-based observers or reinforcement learning approach could present some interesting control features. Furthermore, future researches should include experimental validation, regulation in faulty condition and stability analysis of the neural controller. In addition, the many tools that have so far been developed for diagnosis, decision, control and adaptive control should be commingle for further implementation of active fault tolerant control strategy.

\section{Acknowledgments}

This project has received financial support from the Reunion Island Region and the European Union - European Regional Development Fund (ERDF) OP 2014-2020. 
Appendix A.

Table A.2: A summary of adaptive neural controllers applied for PEMFC.

\begin{tabular}{|c|c|c|c|c|c|c|c|}
\hline $\begin{array}{l}\text { Control } \\
\text { method }\end{array}$ & Application & $\begin{array}{l}\text { Sample } \\
\text { time }\end{array}$ & $\begin{array}{l}\text { Neural } \\
\text { type }\end{array}$ & $\begin{array}{l}\text { Neural } \\
\text { input(s) }\end{array}$ & $\begin{array}{l}\text { Neural } \\
\text { output(s) }\end{array}$ & $\begin{array}{l}\text { Adaptive } \\
\text { strategy }\end{array}$ & $\begin{array}{l}\text { Set point(s) } \\
\text { Test case }\end{array}$ \\
\hline \multirow[t]{2}{*}{ Neural-Inverse } & $\begin{array}{l}\text { Prevents oxygen star- } \\
\text { vation via compressor } \\
\text { voltage [39] }\end{array}$ & - & $\begin{array}{l}\text { Recurrent } \\
\text { fuzzy }\end{array}$ & $\begin{array}{l}\text { Required air supply } \\
\text { manifold flow } \\
\text { Previous required air } \\
\text { supply manifold flow }\end{array}$ & Compressor voltage & $\begin{array}{l}\text { Recurrent fuzzy param- } \\
\text { eters by BP based GD }\end{array}$ & $\begin{array}{l}\text { Set } \lambda_{O_{2}}=2 \quad \text { current } \\
\text { Load } \\
1.2-2 \mathrm{~kJ} / \mathrm{A} \quad \\
\text { Test duration } 100 \mathrm{~s}\end{array}$ \\
\hline & $\begin{array}{l}\text { Power regulation via } \\
\text { hydrogen humidity [50] }\end{array}$ & - & Wavelet & Power $\mathrm{p}-\mathrm{u}$ & Hydrogen humidity & Neural weights by LS & $\begin{array}{l}\text { Set } P=0.5-1 p u \\
\text { Test duration } 150 \mathrm{~s}\end{array}$ \\
\hline \multirow[t]{6}{*}{ Neural-Hybrid } & $\begin{array}{l}\text { Stabilize stack voltage } \\
\text { via air partial pressure } \\
\text { [53] }\end{array}$ & $2 s$ & ML & Desired voltage & Air partial pressure & ML weights by GD & $\begin{array}{l}\text { Set voltage } 57 \mathrm{~V} \\
\text { Load current } 18-33 \mathrm{~A} \\
\text { Test duration } 500 \mathrm{~s}\end{array}$ \\
\hline & $\begin{array}{l}\text { Stabilize voltage via } \\
\text { methane flow rate [54] }\end{array}$ & - & $\mathrm{RBF}$ & Desired voltage & Methane flow rate & $\begin{array}{l}\text { RBF output weights by } \\
\text { adaptive laws }\end{array}$ & $\begin{array}{l}\text { Set voltage } 53 \mathrm{~V} \\
\text { Load current } 70-90 \mathrm{~A} \\
\text { Noise load current } 1 \% \\
\text { variance } \\
\text { Test duration } 150 \mathrm{~s}\end{array}$ \\
\hline & $\begin{array}{l}\text { Maintain oxygen stoi- } \\
\text { chiometry via compres- } \\
\text { sor voltage [55] }\end{array}$ & $0.1 s$ & $\mathrm{RBF}$ & $\begin{array}{l}\text { Previous compressor } \\
\text { voltage } \\
\text { Load current }\end{array}$ & Compressor voltage & $\begin{array}{l}\text { RBF widths and } \\
\text { weights }\end{array}$ & $\begin{array}{l}\text { Set } \lambda_{O_{2}}=2 \\
\text { Load } \\
100-300 \mathrm{~A}\end{array}$ \\
\hline & & & & Previous load current & & & Compressor gain \\
\hline & & & & Previous net power & & & Test duration $30 s$ \\
\hline & & & & $\begin{array}{ll}\text { Previous } & \text { oxygen } \\
\text { stoichiometry } & \end{array}$ & & & \\
\hline \multirow[t]{4}{*}{$\begin{array}{l}\text { Neural- } \\
\text { Feedback }\end{array}$} & $\begin{array}{l}\text { Maintain oxygen stoi- } \\
\text { chiometry via compres- } \\
\text { sor voltage }[57,58]\end{array}$ & $0.002 s$ & B-Spline & $\begin{array}{l}\text { Oxygen stoichiometry } \\
\text { error }\end{array}$ & Compressor voltage & $\begin{array}{l}\text { B-Spline parameters by } \\
\text { instantaneous learning } \\
\text { rule }\end{array}$ & $\begin{array}{l}\text { Set } \lambda_{\mathrm{O}_{2}}=2 \\
\text { Load current } 100- \\
300 \mathrm{~A} \\
\text { Test duration } 30-45 \mathrm{~s}\end{array}$ \\
\hline & Temperature control via & $2 s$ & Fuzzy & Stack temperature error & Hydrogen flowrate & $\mathrm{NN}$ weights by $\mathrm{BP}$ & Set $T=$ \\
\hline & $\begin{array}{l}\text { hydrogen, oxygen and } \\
\text { water cooling flow rates } \\
\text { [59] }\end{array}$ & & & $\begin{array}{l}\text { Time delay temperature } \\
\text { error }\end{array}$ & $\begin{array}{l}\text { Oxygen flowrate } \\
\text { Water cooling flowrate }\end{array}$ & & $80{ }^{\circ} \mathrm{C} \& 100{ }^{\circ} \mathrm{C}$ \\
\hline & $\begin{array}{l}\text { Temperature control via } \\
\text { anode and cathode flow } \\
\text { rates [60] }\end{array}$ & $2 s$ & Fuzzy & $\begin{array}{l}\text { Stack temperature error } \\
\text { Previous stack tempera- } \\
\text { ture error }\end{array}$ & $\begin{array}{l}\text { Anode gas flow rate } \\
\text { Cathode gas flow rate }\end{array}$ & $\begin{array}{l}\text { Fuzzy parameters by } \\
\text { BP }\end{array}$ & $\begin{array}{l}\text { Set temperature } 80{ }^{\circ} \mathrm{C} \\
\text { Test duration } 600 \mathrm{~s}\end{array}$ \\
\hline $\begin{array}{l}\text { Dynamic } \\
\text { Programming }\end{array}$ & $\begin{array}{l}\text { Optimal voltage control } \\
\text { via hydrogen and oxy- } \\
\text { gen partial pressures } \\
\text { [63] }\end{array}$ & - & $\begin{array}{l}\text { Parametric } \\
\text { cerebellar }\end{array}$ & Voltage error & $\begin{array}{l}\text { Hydrogen partial pres- } \\
\text { sure } \\
\text { Oxygen partial pressure }\end{array}$ & $\begin{array}{l}\text { Parametric cerebellar } \\
\text { weights by GD }\end{array}$ & $\begin{array}{l}\text { Set voltage } 24-28 \mathrm{~V} \\
\text { Load current } 5-25 \mathrm{~A} \\
\text { Test duration } 300 \mathrm{~s}\end{array}$ \\
\hline
\end{tabular}




\begin{tabular}{|c|c|c|c|c|c|c|c|}
\hline $\begin{array}{l}\text { Control } \\
\text { method }\end{array}$ & Application & $\begin{array}{l}\text { Sample } \\
\text { time }\end{array}$ & $\begin{array}{l}\text { Neural } \\
\text { type }\end{array}$ & $\begin{array}{l}\text { Neural } \\
\text { input(s) }\end{array}$ & $\begin{array}{l}\text { Neural } \\
\text { output(s) }\end{array}$ & $\begin{array}{l}\text { Adaptive } \\
\text { strategy }\end{array}$ & $\begin{array}{l}\text { Set point(s) } \\
\text { Test case }\end{array}$ \\
\hline \multirow[t]{5}{*}{$\begin{array}{l}\text { Proportional } \\
\text { Integral Deriva- } \\
\text { tive }\end{array}$} & $\begin{array}{l}\text { Maintain oxygen stoi- } \\
\text { chiometry via air mass } \\
\text { flow rate }[23,65,66]\end{array}$ & $3 s$ & $\begin{array}{l}\text { Non-linear } \\
\text { auto-regressive }\end{array}$ & $\begin{array}{l}\text { Previous air stoichiom- } \\
\text { etry } \\
\text { Previous air mass flow } \\
\text { rate }\end{array}$ & $\begin{array}{l}\text { Predict air stoichiome- } \\
\text { try }\end{array}$ & $\begin{array}{l}\text { PID parameters by gen- } \\
\text { eralized minimum vari- } \\
\text { ance }\end{array}$ & $\begin{array}{l}\text { Set } \lambda_{\mathrm{O}_{2}}=2-5 \\
\text { Load current } 15-25 \mathrm{~A} \\
\text { Test duration } 750- \\
3000 \mathrm{~s}\end{array}$ \\
\hline & $\begin{array}{l}\text { Power tracking via inlet } \\
\text { reactants }[50,68]\end{array}$ & - & Wavelet & Inlet reactants & Derivative power $\mathrm{p}-\mathrm{u}$ & Neural weights by LS & $\begin{array}{l}\text { Set } P=0.8-1 p u \\
\text { Test duration } 50 \mathrm{~s}\end{array}$ \\
\hline & $\begin{array}{l}\text { Power tracking via air } \\
\text { inlet pressure [69] }\end{array}$ & - & Elmann & $\begin{array}{l}\text { Output power } \\
\text { Air mass flow } \\
\text { Air temperature }\end{array}$ & Predict air pressure & $\begin{array}{l}\text { Elmann weights by BP } \\
\text { and predicted air pres- } \\
\text { sure error }\end{array}$ & $\begin{array}{l}\text { Set } P_{\text {air }}=0-1 \mathrm{kPa} \\
\text { Load current } 20-100 \% \\
\text { Test duration } 4 \mathrm{~s}\end{array}$ \\
\hline & & & Elmann & $\begin{array}{l}\text { Predicted air pressure } \\
\text { error } \\
\text { Change of air partial er- } \\
\text { ror }\end{array}$ & PID parameters & & \\
\hline & $\begin{array}{l}\text { Temperature control via } \\
\text { gas heating resistance } \\
\text { [72] }\end{array}$ & - & ML & $\begin{array}{l}\text { Desired temperature } \\
\text { Measured temperature }\end{array}$ & $\begin{array}{l}\text { Gas heating device in- } \\
\text { put }\end{array}$ & Neural weights by BP & $\begin{array}{l}\text { Set } T=40{ }^{\circ} \mathrm{C} \\
\text { Test duration } 30 \mathrm{~min}\end{array}$ \\
\hline \multirow[t]{2}{*}{ Linearization } & $\begin{array}{l}\text { Maintain oxygen stoi- } \\
\text { chiometry via compres- } \\
\text { sor voltage [74] }\end{array}$ & - & ML & $\begin{array}{l}\text { Oxygen mass flow } \\
\text { Hydrogen mass flow } \\
\text { Nitrogen mass flow } \\
\text { Current }\end{array}$ & Stack voltage & ML weights by BP & $\begin{array}{l}\text { Set } \lambda_{O_{2}}=2 \\
\text { Load current } 25-140 \mathrm{~A} \\
\text { Test duration } 30 \mathrm{~s}\end{array}$ \\
\hline & $\begin{array}{l}\text { Stabilize partial pres- } \\
\text { sure via anode and cath- } \\
\text { ode gas flow rates [75] }\end{array}$ & - & ML & $\begin{array}{l}\text { Disturbed gas pressure } \\
\text { Error gas pressure }\end{array}$ & $\begin{array}{l}\text { Compensation for the } \\
\text { nonlinearities and accu- } \\
\text { racy }\end{array}$ & $\begin{array}{l}\text { ML weights by sigma } \\
\text { law }\end{array}$ & $\begin{array}{l}\text { No set information } \\
\text { Load resistance } 0.145- \\
4.123 \Omega \\
\text { Test duration } 45 s\end{array}$ \\
\hline Backstepping & $\begin{array}{l}\text { Maintain oxygen stoi- } \\
\text { chiometry via the com- } \\
\text { pressor voltage [77] }\end{array}$ & - & RBF & $\begin{array}{l}\text { Air pressure of the sup- } \\
\text { ply manifold } \\
\text { Rotational speed of the } \\
\text { compressor }\end{array}$ & $\begin{array}{l}\text { Non-affine function of } \\
\text { air supply subsystem }\end{array}$ & $\begin{array}{l}\text { RBF parameters by } \\
\text { dead-zone projection }\end{array}$ & $\begin{array}{l}\text { Set } \lambda_{O_{2}}=2 \\
\text { Load current } 100- \\
270 \mathrm{~A} \\
\text { Test duration } 30 \mathrm{~s}\end{array}$ \\
\hline
\end{tabular}




\section{Flow Control}

\section{Neural-Inverse}

[39] Paper(s) results

Convergence faster

than PI, less error

(ITAE 162 to 70.1 )

Robust to external

load disturbances.

Stabilize com-

pressor efficiency

$(72 \%-76 \%)$

\section{Observation(s)}

Stability is not en-

sured

$-\quad$ Some overshoots $(0.4$

for $\lambda_{O_{2}}=2$ )

\section{Neural-Hybrid}

[53- Paper(s) results Adaptive to compres-

55] sor gain fault (MAE 0.0078 to 0.0062 )

Robust to external

load disturbances

(standard deviation

$0.2 \%$ to noise vari-

ance of $1 \%$ )

Stability is ensured

\section{Observation(s)}

Some overshoots $(0.8$

for $\lambda_{O_{2}}=2$ )

\section{Neural-Feedback}

[57, Paper(s) results

Less oscillations
and overshoots than

$\mathrm{PI}(0.8$ to 0.6 for

$\lambda_{O_{2}}=2$ )

Best tracking than

static controller

\section{Observation(s)}

Stability is not ensured

\section{Neural-PID}

[23, Paper(s) results

50, Adaptive to mass flow

65, controller fault (Mean

66, RE 13.71 to 1.35)

68] Less overshoots (2 to

1 for $\lambda_{O_{2}}=5$ ) and

better tracking than

PID (Mean RE 5.75

to 1.84 )

\section{Observation(s)}

Stability is not en-

sured

Small variations on

static periods
Neural-Linearization

Neural-Backstepping

[74] Paper(s) results Accurate and fast control response time

[77] Paper(s) results

Smaller settling time, tracking error and overshoots $(0.7$ to 0.4 for $\lambda_{O_{2}}=2$ ) than feed-forward

Less oscillations than PID, rejects disturbances effectively Stability ensured

\section{Observation(s)}

Observation(s)

Stability is not ensured

Tedious derivatives of the virtual control

Table B.4: A summary of adaptive neural controllers applied for PEMFC gas pressure.

overshoots $(0.5$

for $\lambda_{O_{2}}=2$ )

\begin{tabular}{|c|c|c|c|c|c|c|c|c|c|}
\hline \multicolumn{10}{|c|}{ Pressure Control } \\
\hline & Neural-Inverse & & Neural-Hybrid & & Neural-DP & & Neural-PID & & Neural-Linearization \\
\hline [39] & $\begin{array}{l}\text { Paper(s) results } \\
\text { Tight pressure track- } \\
\text { ing }\end{array}$ & [53] & $\begin{array}{l}\text { Paper(s) results } \\
\text { Convergence applied } \\
\text { in very short time, } \\
\text { less errors (MSE } 0.81 \\
\text { to } 0.78 \text { ) } \\
\text { Fewer fluctuations } \\
\text { than PID }\end{array}$ & [63] & $\begin{array}{l}\text { Paper(s) results } \\
\text { Less variations and } \\
\text { better tracking than } \\
\text { PID }\end{array}$ & [69] & $\begin{array}{l}\text { Paper(s) results } \\
\text { Shorter response time } \\
\text { and smaller response } \\
\text { error than PID }\end{array}$ & [75] & $\begin{array}{l}\text { Paper(s) results } \\
\text { Eliminates overshoots } \\
\text { More robust to exter- } \\
\text { nal load disturbances } \\
\text { (error } 16 \% \text { to } 6 \% \text { ) and } \\
\text { against uncertainties } \\
\text { (reduce oscillation by } \\
40 \% \text { ) than PI }\end{array}$ \\
\hline & Observation(s) & & Observation(s) & & Observation(s) & & Observation(s) & & Observation(s) \\
\hline & $\begin{array}{l}\text { Stability is not } \\
\text { analyzed }\end{array}$ & & $\begin{array}{l}\text { Stability is not } \\
\text { analyzed }\end{array}$ & & $\begin{array}{l}\text { Stability is not } \\
\text { analyzed }\end{array}$ & & $\begin{array}{l}\text { Stability is not } \\
\text { analyzed }\end{array}$ & & $\begin{array}{l}\text { Consecutive differ- } \\
\text { entiation of system } \\
\text { output }\end{array}$ \\
\hline
\end{tabular}


Table B.5: A summary of adaptive neural controllers applied for PEMFC temperature.

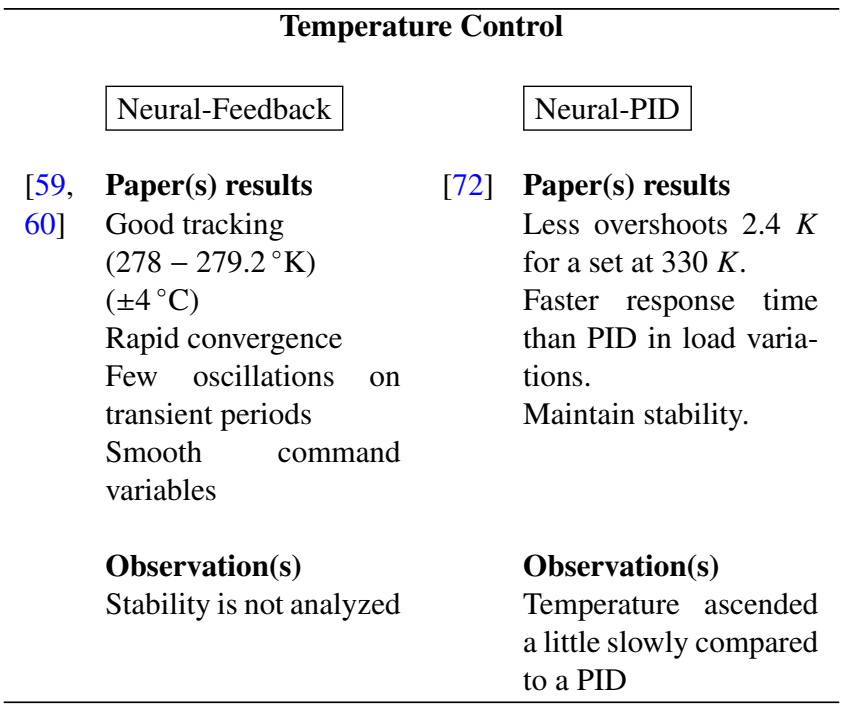

Table B.6: A summary of adaptive neural controllers applied for PEMFC humidity.

\section{Humidity Control}

Neural-PID

[50] $\operatorname{Paper}(\mathbf{s})$ results

Some overshoots and

oscillations on static

period

Convergence time is a

few second

Observation(s)

Stability is not analyzed 


\section{References}

[1] S. R. Dhanushkodi, Life Cycle Analysis of Fuel Cell Technology, Journal of Environmental Informatics 11 (1) (2008) 36-44. doi:10.3808/jei.200800109.

URL http://www.iseis.org/JEI/abstract.asp?no= 200800109

[2] H. Jiang, L. Wei, X. Fan, J. Xu, W. Shyy, T. Zhao, A novel energy storage system incorporating electrically rechargeable liquid fuels as the storage medium, Science Bulletindoi:10.1016/j.scib.2019.01.014.

URL https://linkinghub.elsevier.com/retrieve/pii/ S2095927319300544

[3] W. Liu, E. Setijadi, L. Crema, R. Bartali, N. Laidani, K. AgueyZinsou, G. Speranza, Carbon nanostructures/Mg hybrid materials for hydrogen storage, Diamond and Related Materials 82 (2018) 19-24. doi:10.1016/j.diamond.2017.12.003.

URL https://linkinghub.elsevier.com/retrieve/pii/ S0925963517305733

[4] M. Davids, M. Lototskyy, M. Malinowski, D. van Schalkwyk, A. Parsons, S. Pasupathi, D. Swanepoel, T. van Niekerk, Metal hydride hydrogen storage tank for light fuel cell vehicle, International Journal of Hydrogen Energydoi: 10.1016/j . i jhydene.2019.01.227. URL https://linkinghub.elsevier.com/retrieve/pii/ S0360319919304082

[5] R. Ahluwalia, J. Peng, H. Roh, T. Hua, C. Houchins, B. James, Supercritical cryo-compressed hydrogen storage for fuel cell electric buses, International Journal of Hydrogen Energy 43 (22) (2018) 10215-10231. doi:10.1016/j.ijhydene.2018.04.113.

URL https://linkinghub.elsevier.com/retrieve/pii/ S0360319918312709

[6] E. Ogungbemi, O. Ijaodola, F. Khatib, T. Wilberforce, Z. El Hassan, J. Thompson, M. Ramadan, A. Olabi, Fuel cell membranes Pros and cons, Energy 172 (2019) 155-172. doi:10.1016/j.energy.2019.01.034.

URL https://linkinghub.elsevier.com/retrieve/pii/ S0360544219300362

[7] P. K. Mohanta, M. S. Ripa, F. Regnet, L. Jrissen, Dependency of membrane types, catalyst layer thickness and ionomer contents on MEA performances of PEMFC, 8th International Conference on Fundamentals and Development of Fuel Cells (FDFC2019).

[8] T. Chen, S. Liu, J. Zhang, M. Tang, Study on the characteristics of GDL with different PTFE content and its effect on the performance of PEMFC, International Journal of Heat and Mass Transfer 128 (2019) 1168-1174. doi:10.1016/j.ijheatmasstransfer.2018.09.097. URL https://linkinghub.elsevier.com/retrieve/pii/ S0017931018323640

[9] M. Balakrishnan, L. Eifert, R. Zeis, B. D. Hatton, A. Bazylak, Electrospun nano-fibrous gas diffusion layers with graded pore-sizes for polymer electrolyte membrane fuel cells, 8th International Conference on Fundamentals and Development of Fuel Cells (FDFC2019).

[10] L. Xing, Y. Wang, P. K. Das, K. Scott, W. Shi, Homogenization of current density of PEM fuel cells by in-plane graded distributions of platinum loading and GDL porosity, Chemical Engineering Science 192 (2018) 699-713. doi:10.1016/j.ces.2018.08.029.

URL https://linkinghub.elsevier.com/retrieve/pii/ S0009250918305980

[11] A. Valente, D. Iribarren, J. Dufour, End of life of fuel cells and hydrogen products: From technologies to strategies, International Journal of Hydrogen Energydoi:10.1016/j.ijhydene.2019.01.110. URL https://linkinghub.elsevier.com/retrieve/pii/ S0360319919302423

[12] M. Yue, S. Jemei, N. Zerhouni, Developing a Health-Conscious Energy Management Strategy based on Prognostics for a Fuel cell Hybrid Electric Vehicle, 8th International Conference on Fundamentals and Development of Fuel Cells (FDFC2019).

[13] M. Grandjacques, M. Grard, Online indicators of fuel cell degradation in real uses, 8th International Conference on Fundamentals and Development of Fuel Cells (FDFC2019).

[14] K. Chen, S. Laghrouche, A. Djerdir, Proton Exchange Membrane Fuel Cell Prognostics Using Genetic Algorithm and Extreme Learning Machine, 8th International Conference on Fundamentals and Development of Fuel Cells (FDFC2019).
[15] N. F. Asri, T. Husaini, A. B. Sulong, E. H. Majlan, W. R. W. Daud, Coating of stainless steel and titanium bipolar plates for anticorrosion in PEMFC: A review, International Journal of Hydrogen Energy 42 (14) (2017) 9135-9148. doi:10.1016/j .ijhydene.2016.06.241.

URL https://linkinghub.elsevier.com/retrieve/pii/ S0360319915311708

[16] M. Beasley, Reliability for engineers: an introduction, Macmillan, London, 1991.

[17] A. Benmouna, M. Becherif, D. Depernet, F. Gustin, H. Ramadan, S. Fukuhara, Fault diagnosis methods for Proton Exchange Membrane Fuel Cell system, International Journal of Hydrogen Energy 42 (2) (2017) 1534-1543. doi:10.1016/j.ijhydene.2016.07.181. URL http://linkinghub.elsevier.com/retrieve/pii/ S0360319916307364

[18] Y. Zhang, J. Jiang, Bibliographical review on reconfigurable faulttolerant control systems, Annual Reviews in Control 32 (2) (2008) 229-252. doi:10.1016/j.arcontrol.2008.03.008.

URL http://linkinghub.elsevier.com/retrieve/pii/ S1367578808000345

[19] X. Wu, D. Gao, Optimal fault-tolerant control strategy of a solid oxide fuel cell system, Journal of Power Sources 364 (2017) 163-181. doi:10.1016/j.jpowsour.2017.08.017.

URL http://linkinghub.elsevier.com/retrieve/pii/ S0378775317310418

[20] D. Rotondo, F. Nejjari, V. Puig, Fault tolerant control of a proton exchange membrane fuel cell using TakagiSugeno virtual actuators, Journal of Process Control 45 (2016) 12-29. doi:10.1016/j.jprocont.2016.06.001.

URL http://linkinghub.elsevier.com/retrieve/pii/ S0959152416300671

[21] X. Wu, B. Zhou, Fault tolerance control for proton exchange membrane fuel cell systems, Journal of Power Sources 324 (2016) 804-829. doi:10.1016/j.jpowsour.2016.05.066.

URL http://linkinghub.elsevier.com/retrieve/pii/ S0378775316306127

[22] D. Guilbert, A. Gaillard, A. N'Diaye, A. Djerdir, Fault-tolerant control for PEMFC and its DC/DC converter, in: Energy (IYCE), 2015 th International Youth Conference on, IEEE, 2015, pp. 1-6.

[23] C. Lebreton, M. Benne, C. Damour, N. Yousfi-Steiner, B. GrondinPerez, D. Hissel, J.-P. Chabriat, Fault Tolerant Control Strategy applied to PEMFC water management, International Journal of Hydrogen Energy 40 (33) (2015) 10636-10646. doi:10.1016/j.ijhydene.2015.06.115.

URL http://linkinghub.elsevier.com/retrieve/pii/ S0360319915016006

[24] E. Dijoux, M. Benne, N. Y. Steiner, B. G. Prez, M.-C. Pra, Active fault tolerant control strategy applied to PEMFC systems, IEEE, 2017.

[25] G. Niu, S. Liu, Demagnetization monitoring and life extending control for permanent magnet-driven traction systems, Mechanical Systems and Signal Processing 103 (2018) 264-279. doi: $10.1016 / j \cdot y m s s p .2017 .10 .003$.

URL http://linkinghub.elsevier.com/retrieve/pii/ S0888327017305290

[26] A. D. Shum, D. Y. Parkinson, X. Xiao, A. Z. Weber, O. S. Burheim, I. V. Zenyuk, Investigating PhaseChangeInduced Flow in Gas Diffusion Layers in Fuel Cells with Xray Computed Tomography, Electrochimica Acta 256 (2017) 279-290. doi:10.1016/j.electacta.2017.10.012.

URL http://linkinghub.elsevier.com/retrieve/pii/ S0013468617320704

[27] T. V. Nguyen, A Water and Heat Management Model for ProtonExchange-Membrane Fuel Cells, Journal of The Electrochemical Society 140 (8) (1993) 2178. doi : 10.1149/1.2220792. URL http://jes.ecsdl.org/cgi/doi/10.1149/1.2220792

[28] D. N. Ozen, B. Timurkutluk, K. Altinisik, Effects of operation temperature and reactant gas humidity levels on performance of PEM fuel cells, Renewable and Sustainable Energy Reviews 59 (2016) 1298-1306. doi:10.1016/j.rser.2016.01.040.

URL http://linkinghub.elsevier.com/retrieve/pii/ S1364032116000708

[29] P. Rama, R. Chen, J. Andrews, A review of performance degradation 
and failure modes for hydrogen-fuelled polymer electrolyte fuel cells.

[30] Z. Lu, S. Kandlikar, C. Rath, M. Grimm, W. Domigan, A. White, M. Hardbarger, J. Owejan, T. Trabold, Water management studies in PEM fuel cells, Part II: Ex situ investigation of flow maldistribution, pressure drop and two-phase flow pattern in gas channels, International Journal of Hydrogen Energy 34 (8) (2009) 3445-3456. doi: $10.1016 / j$.ijhydene.2008.12.025.

URL http://linkinghub.elsevier.com/retrieve/pii/ S0360319908016741

[31] G. H. Guvelioglu, H. G. Stenger, Flow rate and humidification effects on a PEM fuel cell performance and operation, Journal of Power Sources 163 (2) (2007) 882-891. doi:10.1016/j . jpowsour.2006.09.052. URL http://linkinghub.elsevier.com/retrieve/pii/ S0378775306020404

[32] S. Rak-Hyun, Effect of flow rate and starvation of reactant gases on the performance of phosphoric acid fuel cells.

[33] J. Zhang, G. Liu, W. Yu, M. Ouyang, Adaptive control of the airflow of a PEM fuel cell system, Journal of Power Sources 179 (2) (2008) 649-659. doi:10.1016/j.jpowsour.2008.01.015.

URL http://linkinghub.elsevier.com/retrieve/pii/ S0378775308001067

[34] S. Ou, L. E. K. Achenie, Artificial Neural Network Modeling of PEM Fuel Cells, Journal of Fuel Cell Science and Technology 2 (4) (2005) 226. doi:10.1115/1.2039951.

URL http://FuelCellScience.asmedigitalcollection. asme.org/article.aspx?articleid=1471796

[35] S. Ou, L. Achenie, A hybrid neural network model for PEM fuel cells, Journal of Power Sources 140 (2) (2005) 319-330. doi: $10.1016 / j \cdot j$ powsour.2004.08.047.

URL http://linkinghub.elsevier.com/retrieve/pii/ S0378775304009437

[36] F. da Costa Lopes, S. Kelouwani, L. Boulon, K. Agbossou, N. Marx, K. Ettihir, Neural network modeling strategy applied to a multi-stack PEM fuel cell system, in: Transportation Electrification Conference and Expo (ITEC), 2016 IEEE, IEEE, 2016, pp. 1-7.

[37] L. Huang, S. Quan, H. Xu, Q. Wang, Modeling and Simulation of the Fuel Cell Air Supply System Based on Artificial Neural Network, IEEE, 2008, pp. 493-497. doi : 10.1109/PACIIA. 2008. 298. URL http: //ieeexplore.ieee.org/document/4756824/

[38] G. Dede, M. H. Sazl, Speech recognition with artificial neural networks, Digital Signal Processing 20 (3) (2010) 763-768. doi:10.1016/j.dsp.2009.10.004.

URL http://linkinghub.elsevier.com/retrieve/pii/ S1051200409001821

[39] C.-h. Li, X.-j. Zhu, S. Sui, W.-q. Hu, M.-r. Hu, Adaptive inverse control of air supply flow for proton exchange membrane fuel cell systems, Journal of Shanghai University (English Edition) 13 (6) (2009) 474-480. doi:10.1007/s11741-009-0610-3.

URL http://link.springer.com/10.1007/ s11741-009-0610-3

[40] C. Liu, D. Wang, E. D. Goodman, Q. Chen, Adaptive Walking Control of Biped Robots Using Online Trajectory Generation Method Based on Neural Oscillators, Journal of Bionic Engineering 13 (4) (2016) 572-584. doi:10.1016/S1672-6529(16)60329-3.

URL http://linkinghub.elsevier.com/retrieve/pii/ S1672652916603293

[41] P. Manoonpong, U. Parlitz, F. Wrgtter, Neural control and adaptive neural forward models for insect-like, energy-efficient, and adaptable locomotion of walking machines, Frontiers in Neural Circuits 7. doi:10.3389/fncir.2013.00012.

URL http://journal.frontiersin.org/article/10.3389/ fncir.2013.00012/abstract

[42] N. Sundararajan, P. Saratchandran, Y. Li, Fully Tuned Radial Basis Function Neural Networks for Flight Control, Springer US, Boston, MA, 2002. doi : 10.1007/978-1-4757-5286-1.

URL 978-1-4757-5286-1

[43] R. Lungu, M. Lungu, Adaptive flight control law based on neural networks and dynamic inversion for micro-aerial vehicles, Neurocomputing 199 (2016) 40-49. doi : 10.1016/j.neucom.2015.12.118. URL http://linkinghub.elsevier.com/retrieve/pii/
S0925231216003581

[44] E. Buzi, P. Marango, A Comparison of conventional and nonconventional methods of DC motor speed control, IFAC Proceedings Volumes 46 (8) (2013) 50-53. doi:10.3182/20130606-3-XK-4037.00054. URL http://linkinghub.elsevier.com/retrieve/pii/ S1474667016342124

[45] L. Sun, Analysis and Comparison of Variable Structure Fuzzy Neural Network Control and the PID Algorithm.

[46] B. Dehghan, B. W. Surgenor, Comparison of fuzzy and neural network adaptive methods for the position control of a pneumatic system, in: Electrical and Computer Engineering (CCECE), 2013 26th Annual IEEE Canadian Conference on, IEEE, 2013, pp. 1-4.

[47] R. Y. Adhitya, M. A. Ramadhan, S. Kautsar, N. Rinanto, S. T. Sarena, I. Munadhif, M. Syai'in, R. T. Soelistijono, A. Soeprijanto, Comparison methods of Fuzzy Logic Control and Feed Forward Neural Network in automatic operating temperature and humidity control system (Oyster Mushroom Farm House) using microcontroller, in: Electronics and Smart Devices (ISESD), International Symposium on, IEEE, 2016, pp. $168-173$.

[48] F.-J. Lin, R.-F. Fung, R.-J. Wai, Comparison of sliding-mode and fuzzy neural network control for motor-toggle servomechanism, IEEE/ASME transactions on mechatronics 3 (4) (1998) 302-318.

[49] F. Lamnabhi-Lagarrigue, A. Annaswamy, S. Engell, A. Isaksson, P. Khargonekar, R. M. Murray, H. Nijmeijer, T. Samad, D. Tilbury, P. Van den Hof, Systems \& Control for the future of humanity, research agenda: Current and future roles, impact and grand challenges, Annual Reviews in Control 43 (2017) 1-64. doi:10.1016/j.arcontrol.2017.04.001.

URL http://linkinghub.elsevier.com/retrieve/pii/ S1367578817300573

[50] M. Sedighizadeh, A. Rezazadeh, Adaptive Self-Tuning Wavelet Neural Network Controller for a Proton Exchange Membrane Fuel Cell, in: J. Kacprzyk, J. Schumann, Y. Liu (Eds.), Applications of Neural Networks in High Assurance Systems, Vol. 268, Springer Berlin Heidelberg, Berlin, Heidelberg, 2010, pp. 221-245. doi : $10.1007 / 978-3-642-10690-3 \_11$.

URL http://link.springer.com/10.1007/ 978-3-642-10690-3_11

[51] M. A. Shafiq, Direct adaptive inverse control of nonlinear plants using neural networks, in: Future Technologies Conference (FTC), IEEE, 2016, pp. 827-830.

[52] J. P. Jordanou, E. A. Antonelo, E. Camponogara, M. A. S. d. Aguiar, Recurrent Neural Network Based Control Of An Oil Well.

[53] S. M. Rakhtala, R. Ghaderi, A. Ranjbar Noei, Proton exchange membrane fuel cell voltage-tracking using artificial neural networks, Journal of Zhejiang University SCIENCE C 12 (4) (2011) 338-344. doi:10.1631/jzus. C0910683.

URL http://www.springerlink.com/index/10.1631/jzus. C0910683

[54] A. Rezazadeh, A. Askarzadeh, M. Sedighizadeh, Adaptive Inverse Control of Proton Exchange Membrane Fuel Cell Using RBF Neural Network.

[55] O. Ragb, Adaptive Feed-forward and Feedback control using neural networks for oxygen ratio in Fuel cell stacks.

[56] N. N. Son, C. V. Kien, H. P. H. Anh, A novel adaptive feed-forward-PID controller of a SCARA parallel robot using pneumatic artificial muscle actuator based on neural network and modified differential evolution algorithm, Robotics and Autonomous Systems 96 (2017) 65-80. doi: 10.1016/j.robot.2017.06.012.

URL http://linkinghub.elsevier.com/retrieve/pii/ S0921889016304407

[57] V. M. Sanchez, R. Barbosa, L. Arriaga, J. M. Ramirez, Real time control of air feed system in a PEM fuel cell by means of an adaptive neural-network, International Journal of Hydrogen Energy 39 (29) (2014) 16750-16762. doi:10.1016/j.ijhydene.2014.05.153. URL http://linkinghub.elsevier.com/retrieve/pii/ S0360319914015651

[58] V. Sanchez, J. M. Ramrez, G. Arriaga, On-line air supply control of PEM fuel cell by an adaptive neural network, in: North American Power Symposium (NAPS), 2010, IEEE, 2010, pp. 1-6.

URL http://ieeexplore.ieee.org/abstract/document/ 
$5619596 /$

[59] W. Dong, G.-Y. Cao, X.-J. Zhu, Nonlinear modelling and adaptive fuzzy control of PEMFC (2003) 9

[60] S. Tao, Y. Si-jia, C. Guang-yi, Z. Xin-jian, Modelling and control PEMFC using fuzzy neural networks, Journal of Zhejiang UniversitySCIENCE A 6 (10) (2005) 1084-1089. doi:10.1631/jzus. 2005. A1084.

URL http://link.springer.com/10.1631/jzus.2005.A1084

[61] M. Shirzadeh, A. Amirkhani, A. Jalali, M. R. Mosavi, An indirect adaptive neural control of a visual-based quadrotor robot for pursuing a moving target, ISA Transactions 59 (2015) 290-302. doi:10.1016/j.isatra.2015.10.011.

URL http://linkinghub.elsevier.com/retrieve/pii/ S0019057815002451

[62] R. Jon, Z. Wang, C. Luo, M. Jong, Adaptive robust speed control based on recurrent elman neural network for sensorless PMSM servo drives, Neurocomputing 227 (2017) 131-141. doi:10.1016/j.neucom.2016.09.095.

URL http://linkinghub.elsevier.com/retrieve/pii/ S0925231216313455

[63] P. Almeida, M. Simoes, Neural Optimal Control of PEM Fuel Cells With Parametric CMAC Networks, IEEE Transactions on Industry Applications 41 (1) (2005) 237-245. doi : 10.1109/TIA . 2004.836135. URL http: //ieeexplore.ieee.org/document/1388683/

[64] Y.-C. Bo, X. Zhang, Online adaptive dynamic programming based on echo state networks for dissolved oxygen control, Applied Soft Computing 62 (2018) 830-839. doi:10.1016/j . asoc. 2017.09.015. URL http://linkinghub.elsevier.com/retrieve/pii/ S1568494617305549

[65] C. Lebreton, C. Damour, M. Benne, B. Grondin-Perez, J.-P. Chabriat, Passive Fault Tolerant Control of PEMFC air feeding system, International Journal of Hydrogen Energy 41 (34) (2016) 15615-15621. doi:10.1016/j.ijhydene.2016.06.210.

URL http://linkinghub.elsevier.com/retrieve/pii/ S0360319916304153

[66] C. Damour, M. Benne, B. Grondin-Perez, J.-P. Chabriat, Neural ModelBased Self-Tuning PID Strategy Applied to PEMFC, Engineering 06 (04) (2014) 159-168. doi : 10.4236/eng . 2014.64019.

URL http://www.scirp.org/journal/doi.aspx?DOI=10. 4236/eng. 2014.64019

[67] D. Xu, W. Yan, N. Ji, RBF neural network based adaptive constrained PID control of a solid oxide fuel cell, in: Control and Decision Conference (CCDC), 2016 Chinese, IEEE, 2016, pp. 3986-3991.

[68] M. Sedighizadeh, A. Rezazadeh, A Neuro Adaptive Control Strategy for Movable Power Source of Proton Exchange Membrane Fuel Cell Using Wavelets, International Journal of Energy and Power Engineering 1 (12) (2007) 5.

[69] W. Guoai, Q. Shuhai, C. Qihong, Z. Liyan, S. Lin, Neural-PID Control of Air Pressure in Fuel Cells, IEEE, 2010, pp. 5353-5356. doi:10. 1109/iCECE. 2010.1299.

URL http://ieeexplore.ieee.org/document/5630530/

[70] N. Ji, D. Xu, F. Liu, A novel adaptive neural network constrained control for solid oxide fuel cells via dynamic anti-windup, Neurocomputing 214 (2016) 134-142. doi : 10.1016/j.neucom.2016.05.076.

URL http://linkinghub.elsevier.com/retrieve/pii/ S0925231216305380

[71] Y. Huang, S. Li, J. Sun, Mars entry fault-tolerant control via neural network and structure adaptive model inversion, Advances in Space Researchdoi:10.1016/j.asr.2018.09.016.

URL https://linkinghub.elsevier.com/retrieve/pii/ S0273117718307129

[72] Y. Li, H. Wang, Z. Dai, Using artificial neural network to control the temperature of fuel cell, in: Communications, Circuits and Systems Proceedings, 2006 International Conference on, Vol. 3, IEEE, 2006, pp. 2159-2162.

[73] A. Zribi, M. Chtourou, M. Djemel, A New PID Neural Network Controller Design for Nonlinear Processes.

[74] L. Zhang, M. Pan, S. Quan, Q. Chen, Y. Shi, Adaptive neural control based on pemfc hybrid modeling, in: Intelligent Control and Automation, 2006. WCICA 2006. The Sixth World Congress on, Vol. 2, IEEE, 2006, pp. 8319-8323.
URL http://ieeexplore.ieee.org/abstract/document/ 1713598/

[75] A. Abbaspour, A. Khalilnejad, Z. Chen, Robust adaptive neural network control for PEM fuel cell, International Journal of Hydrogen Energy 41 (44) (2016) 20385-20395. doi: 10.1016/j.ijhydene.2016.09.075.

URL http://linkinghub.elsevier.com/retrieve/pii/ S0360319916327823

[76] S. Mumtaz, S. Ahmad, L. Khan, S. Ali, T. Kamal, S. Hassan, Adaptive Feedback Linearization Based NeuroFuzzy Maximum Power Point Tracking for a Photovoltaic System, Energies 11 (3) (2018) 606. doi: 10.3390/en11030606.

URL http: //www .mdpi . com/1996-1073/11/3/606

[77] P. Li, J. Chen, T. Cai, B. Zhang, Adaptive control of air delivery system for PEM fuel cell using backstepping, in: Control Conference (ASCC), 2011 8th Asian, IEEE, 2011, pp. 1282-1287.

URL http://ieeexplore.ieee.org/abstract/document/ $5899257 /$

[78] J. H. Lee, J. Shin, M. J. Realff, Machine learning: Overview of the recent progresses and implications for the process systems engineering field, Computers \& Chemical Engineeringdoi:10.1016/j.compchemeng.2017.10.008.

URL http://linkinghub.elsevier.com/retrieve/pii/ S0098135417303538

[79] P. L. Galdmez, W. Raveane, A. Gonzlez Arrieta, A brief review of the ear recognition process using deep neural networks, Journal of Applied Logic 24 (2017) 62-70. doi:10.1016/j.jal.2016.11.014.

URL http://linkinghub.elsevier.com/retrieve/pii/ S1570868316300684

[80] W. Yang, Q. Liu, S. Wang, Z. Cui, X. Chen, L. Chen, N. Zhang, Down Image Recognition Based on Deep Convolutional Neural Network, Information Processing in Agriculturedoi:10.1016/j.inpa.2018.01.004.

URL http://linkinghub.elsevier.com/retrieve/pii/ S2214317317302159

[81] P. Bawane, S. Gadariye, S. Chaturvedi, A. A. Khurshid, Object and Character Recognition Using Spiking Neural Network, Materials Today: Proceedings 5 (1) (2018) 360-366.

[82] L. BuÅoniu, T. de Bruin, D. Toli, J. Kober, I. Palunko, Reinforcement learning for control: Performance, stability, and deep approximators, Annual Reviews in Control 46 (2018) 8-28. doi:10.1016/j.arcontrol.2018.09.005.

URL https://linkinghub.elsevier.com/retrieve/pii/ S1367578818301184

[83] H. Kazmi, F. Mehmood, S. Lodeweyckx, J. Driesen, Gigawatt-hour scale savings on a budget of zero: Deep reinforcement learning based optimal control of hot water systems, Energy 144 (2018) 159-168.

[84] W. Liu, G. Qin, Y. He, F. Jiang, Distributed Cooperative Reinforcement Learning-Based Traffic Signal Control That Integrates V2x Networks Dynamic Clustering, IEEE Transactions on Vehicular Technology 66 (10) (2017) 8667-8681. doi:10.1109/TVT . 2017. 2702388. URL http: //ieeexplore.ieee.org/document/7922594/

[85] Y. Jiang, C. Yang, J. Na, G. Li, Y. Li, J. Zhong, A Brief Review of Neural Networks Based Learning and Control and Their Applications for Robots, Complexity 2017 (2017) 1-14. doi : 10.1155/2017/ 1895897.

URL https://www.hindawi.com/journals/complexity/2017/ $1895897 /$

[86] R. Yousefian, S. Kamalasadan, A Review of Neural Network Based Machine Learning Approaches for Rotor Angle Stability Control, arXiv preprint arXiv: 1701.01214 .

[87] F. Barbir, PEM Fuel Cells Theory and Practice, 2005.

[88] B. Gou, B. Diong, W. K. Na, Fuel Cells Modeling, Control, and Applications, 2009.

[89] A. Mohammadi, A. Djerdir, N. Yousfi Steiner, D. Khaburi, Advanced diagnosis based on temperature and current density distributions in a single PEMFC, International Journal of Hydrogen Energy 40 (45) (2015) 15845-15855. doi:10.1016/j.i jhydene.2015.04.157. URL https://linkinghub.elsevier.com/retrieve/pii/ S0360319915010952

[90] M. Hu, G. Cao, Research on the performance differences between a 
standard PEMFC single cell and transparent PEMFC single cells using optimized transparent flow field unitPart II: Performance comparison and explanation, International Journal of Hydrogen Energy 41 (4) (2016) 2967-2980. doi:10.1016/j . ijhydene.2015.12.031.

URL https://linkinghub.elsevier.com/retrieve/pii/ S0360319915307448

[91] Y. Li, X. Zhao, S. Tao, Q. Li, W. Chen, Experimental Study on Anode and Cathode Pressure Difference Control and Effects in a Proton Exchange Membrane Fuel Cell System, Energy Technology 3 (9) (2015) 946-954. doi:10.1002/ente.201500077.

URL http://doi.wiley.com/10.1002/ente. 201500077

[92] A. Sveshnikova, K. Abrosimov, A. Khayrullina, A. Ustinov, Effect of ambient air conditions on PEM fuel cell performance, Journal of Renewable and Sustainable Energy 9 (4) (2017) 044301. doi:10.1063/ 1.5001138 .

URL http: //aip.scitation.org/doi/10.1063/1.5001138

[93] D. Xuan, Z. Li, J. Kim, Y. Kim, Optimal operating points of PEM fuel cell model with RSM, Journal of Mechanical Science and Technology 23 (3) (2009) 717-728. doi : 10.1007/s12206-009-0205-y. URL http://link.springer.com/10.1007/ s12206-009-0205-y

[94] M. L. Doumbia, PEM Fuel Cell Modelling Using Artificial Neural Networks, International Journal of Renewable Energy Research (IJRER) 4 (3) (2014) 725-730.

[95] E. Dijoux, N. Y. Steiner, M. Benne, M.-C. Pra, B. G. Prez, A review of fault tolerant control strategies applied to proton exchange membrane fuel cell systems, Journal of Power Sources 359 (2017) 119-133. doi:10.1016/j.jpowsour.2017.05.058.

URL http://linkinghub.elsevier.com/retrieve/pii/ S0378775317306997

[96] B. Kakati, A. Kucernak, K. Fahy, Using corrosion-like processes to remove poisons from electrocatalysts: a viable strategy to chemically regenerate irreversibly poisoned polymer electrolyte fuel cells, Electrochimica Acta 222 (2016) 888-897. doi:10.1016/j.electacta.2016.11.054.

URL http://linkinghub.elsevier.com/retrieve/pii/ S0013468616323866

[97] S. Zhang, X.-Z. Yuan, J. N. C. Hin, H. Wang, K. A. Friedrich, M. Schulze, A review of platinum-based catalyst layer degradation in proton exchange membrane fuel cells, Journal of Power Sources 194 (2) (2009) 588-600. doi:10.1016/j.jpowsour. 2009.06.073.

URL http://linkinghub.elsevier.com/retrieve/pii/ S037877530901146X

[98] P. K. Bhattacharya, Water flooding in the proton exchange membrane fuel cell (2015) 10.

[99] M. Bodner, C. Hochenauer, V. Hacker, Effect of pinhole location on degradation in polymer electrolyte fuel cells, Journal of Power Sources 295 (2015) 336-348. doi : 10.1016/j.jpowsour. 2015.07.021.

URL http://linkinghub.elsevier.com/retrieve/pii/ S0378775315300690

[100] E. Breaz, F. Gao, A. Miraoui, R. Tirnovan, A short review of aging mechanism modeling of proton exchange membrane fuel cell in transportation applications, in: Industrial Electronics Society, IECON 201440th Annual Conference of the IEEE, IEEE, 2014, pp. 3941-3947.

[101] Z. Wan, H. Chang, S. Shu, Y. Wang, H. Tang, A Review on Cold Start of Proton Exchange Membrane Fuel Cells, Energies 7 (12) (2014) 3179 3203. doi:10.3390/en7053179. URL http: //www.mdpi . com/1996-1073/7/5/3179

[102] M. A. Danzer, S. J. Wittmann, E. P. Hofer, Prevention of fuel cell starvation by model predictive control of pressure, excess ratio, and current, Journal of Power Sources 190 (1) (2009) 86-91. doi:10.1016/j.jpowsour.2008.12.089.

URL http://linkinghub.elsevier.com/retrieve/pii/ S0378775308024749

[103] I. Matraji, S. Laghrouche, M. Wack, Pressure control in a PEM fuel cell via second order sliding mode, International Journal of Hydrogen Energy 37 (21) (2012) 16104-16116. doi:10.1016/j.ijhydene.2012.08.007.

URL http://linkinghub.elsevier.com/retrieve/pii/ S0360319912017739

[104] R. Arif, H. Chu, Y. Ryu, A. Filios, H. Tawfik, K. Shahrabi, An Optimized
Humidity And Temperature Control System For Fuel Cells (2008) 10.

[105] S. Kim, I. Hong, Effects of humidity and temperature on a proton exchange membrane fuel cell (PEMFC) stack, Journal of Industrial and Engineering Chemistry 14 (3) (2008) 357-364. doi: $10.1016 / j \cdot j i e c .2008 .01 .007$.

URL https://linkinghub.elsevier.com/retrieve/pii/ S1226086X08000142

[106] C. Kunde, R. Hanke-Rauschenbach, M. Mangold, A. Kienle, K. Sundmacher, S. Wagner, R. Hahn, Temperature and Humidity Control of a Micro PEM Fuel Cell Stack, Fuel Cells 10 (6) (2010) 949-959. doi:10.1002/fuce.201000022.

URL http: //doi.wiley. com/10.1002/fuce. 201000022

[107] C. Damour, M. Benne, B. Grondin-Perez, J.-P. Chabriat, B. G. Pollet, A novel non-linear model-based control strategy to improve PEMFC water management The flatness-based approach, International Journal of Hydrogen Energy 40 (5) (2015) 2371-2376. doi:10.1016/j.ijhydene.2014.12.052.

URL http://linkinghub.elsevier.com/retrieve/pii/ S0360319914034284

[108] C. Fang, L. Xu, S. Cheng, J. Li, H. Jiang, M. Ouyang, Sliding-modebased temperature regulation of a proton exchange membrane fuel cell test bench, International Journal of Hydrogen Energy 42 (16) (2017) 11745-11757. doi:10.1016/j.ijhydene.2017.03.070.

URL http://linkinghub.elsevier.com/retrieve/pii/ S0360319917309941

[109] M. Karimi, Voltage Control of PEMFC Using A New Controller Based on Reinforcement Learning, International Journal of Information and Electronics Engineeringdoi : 10.7763/IJIEE.2012.V2.200.

URL http: //www.ijiee.org/show-33-166-1.html

[110] J. Zhang, H. Li, J. Zhang, Effect of Operating Backpressure on PEM Fuel Cell Performance, 2009, pp. 65-76. doi:10.1149/1.3271363. URL http://ecst.ecsdl.org/cgi/doi/10.1149/1.3271363

[111] GF135 Digital Mass Flow Controller, Tech. rep., BROOKS instrument (2017).

[112] Mass Flow Controllers, Technical data sheet, SENSIRION the sensor company (2018).

[113] W. Yu, X. Sichuan, H. Ni, Air Compressors for Fuel Cell Vehicles: An Systematic Review, SAE International Journal of Alternative Powertrains 4 (1). doi : $10.4271 / 2015-01-1172$.

URL http://papers.sae.org/2015-01-1172/

[114] A. Cruz Rojas, G. Lopez Lopez, J. Gomez-Aguilar, V. Alvarado, C. Sandoval Torres, Control of the Air Supply Subsystem in a PEMFC with Balance of Plant Simulation, Sustainability 9 (1) (2017) 73. doi: 10.3390/su9010073.

URL http: //www . mdpi . com/2071-1050/9/1/73

[115] R. Bai, Neural network control-based adaptive design for a class of DC motor systems with the full state constraints, Neurocomputing 168 (2015) 65-69. doi:10.1016/j.neucom. 2015.04.090.

URL http://linkinghub.elsevier.com/retrieve/pii/ S0925231215008346

[116] F. Zouari, A. Boulkroune, A. Ibeas, Neural adaptive quantized output-feedback control-based synchronization of uncertain time-delay incommensurate fractional-order chaotic systems with input nonlinearities, Neurocomputing 237 (2017) 200-225. doi: $10.1016 /$ j.neucom.2016.11.036.

URL http://linkinghub.elsevier.com/retrieve/pii/ S0925231216314370

[117] M.-J. Lin, F. Luo, Adaptive neural control of the dissolved oxygen concentration in WWTPs based on disturbance observer, Neurocomputing 185 (2016) 133-141. doi:10.1016/j.neucom. 2015.12.045. URL http://linkinghub.elsevier.com/retrieve/pii/ S0925231215019827

[118] W. He, Z. Yin, C. Sun, Adaptive Neural Network Control of a Marine Vessel With Constraints Using the Asymmetric Barrier Lyapunov Function, IEEE Transactions on Cybernetics 47 (7) (2017) 1641-1651. doi : 10.1109/TCYB. 2016.2554621. URL http://ieeexplore.ieee.org/document/7468475/

[119] K. Warwick, R. Craddock, An introduction to radial basis functions for system identification. A comparison with other neural network methods, in: Decision and Control, 1996., Proceedings of the 35th IEEE Conference on, Vol. 1, IEEE, 1996, pp. 464-469. 
[120] H. Jaeger, Short term memory in echo state networks, in: GMD Report 152,2002

[121] W. Maass, T. Natschlger, H. Markram, Real-time computing without stable states: A new framework for neural computation based on perturbations, Neural computation 14 (11) (2002) 2531-2560.

[122] F. M. Bianchi, S. Scardapane, A. Uncini, A. Rizzi, A. Sadeghian, Prediction of telephone calls load using Echo State Network with exogenous variables, Neural Networks 71 (2015) 204-213. doi:10.1016/j.neunet.2015.08.010.

URL http://linkinghub.elsevier.com/retrieve/pii/ S0893608015001732

[123] F. M. Bianchi, E. Maiorino, M. C. Kampffmeyer, A. Rizzi, R. Jenssen, An overview and comparative analysis of recurrent neural networks for short term load forecasting, arXiv preprint arXiv:1705.04378.

[124] H.-T. Fan, W. Wang, Z. Jin, Performance optimization of echo state networks through principal neuron reinforcement, in: Neural Networks (IJCNN), 2017 International Joint Conference on, IEEE, 2017, pp. 1717-1723.

[125] G. Shi, D. Liu, Q. Wei, Echo state network-based Q-learning method for optimal battery control of offices combined with renewable energy, IET Control Theory \& Applications 11 (7) (2017) 915-922. doi:10.1049/iet-cta.2016.0653.

URL http://digital-library.theiet.org/content/ journals/10.1049/iet-cta.2016.0653

[126] K. Wu, Y. Zhu, Q. Li, G. Han, Algorithm and Implementation of Distributed ESN Using Spark Framework and Parallel PSO, Applied Sciences 7 (4) (2017) 353. doi : 10.3390/app7040353. URL http: //www . mdpi . com/2076-3417/7/4/353

[127] C. Jia, X. Li, K. Wang, D. Ding, Adaptive control of nonlinear system using online error minimum neural networks, ISA Transactions 65 (2016) 125-132. doi:10.1016/j.isatra.2016.07.012.

URL http://linkinghub.elsevier.com/retrieve/pii/ S0019057816301562

[128] D. Sussillo, G. S. Corrado, Resizing neural networks (Jun. 2017).

[129] M. LukoÅeviius, A practical guide to applying echo state networks, in: Neural networks: Tricks of the trade, Springer, 2012, pp. 659-686 URL http://link.springer.com/chapter/10.1007/ 978-3-642-35289-8 36

[130] N. T. Bui, H. Hasegawa, Training Artificial Neural Network Using Modification of Differential Evolution Algorithm, International Journal of Machine Learning and Computing 5 (1) (2015) 1-6. doi:10.7763/ I JMLC . 2015.V5.473

URL http://www.ijmlc.org/index.php?m=content\&c=index\& $\mathrm{a}=$ show\&catid $=49 \& i d=528$

[131] J. Ilonen, J.-K. Kamarainen, J. Lampinen, Differential evolution training algorithm for feed-forward neural networks, Neural Processing Letters 17 (1) (2003) 93-105.

[132] A. Slowik, M. Bialko, Training of artificial neural networks using differential evolution algorithm, in: Human System Interactions, 2008 Conference on, IEEE, 2008, pp. 60-65.

[133] S. S. Ge, C. C. Hang, T. H. Lee, T. Zhang, Stable Adaptive Neural Network Control, Springer US, Boston, MA, 2002. doi : 10.1007/978-1-4757-6577-9.

URL http://link.springer.com/10.1007/ 978-1-4757-6577-9

[134] F. L. Lewis, T. Parisini, Guest editorial: Neural network feedback control with guaranteed stability, International Journal of Control 70 (3) (1998) 337-339. doi:10.1080/002071798222262.

URL http://www.tandfonline.com/doi/abs/10.1080/ 002071798222262

[135] C. Mu, D. Wang, H. He, Novel iterative neural dynamic programming for data-based approximate optimal control design, Automatica 81 (2017) 240-252. doi : 10.1016/j . automatica.2017.03.022. URL http://linkinghub.elsevier.com/retrieve/pii/ S0005109817301450

[136] J. M. Igreja, J. M. Lemos, S. J. Costa, Adaptive feedback linearizing control for transport phenomena processes.

[137] L. Jin, M. Gupta, Globally asymptotical stability of discrete-time analog neural networks, IEEE Transactions on Neural Networks 7 (4) (1996) 1024-1031. doi:10.1109/72.508944. URL http: //ieeexplore.ieee.org/document/508944/
[138] P. Khlaeo-om, S. Kuntanapreeda, A Stability Condition for Neural Network Control of Uncertain Systems (2005) 6.

[139] K. H. Lim, K. P. Seng, L.-M. Ang, S. W. Chin, Lyapunov Theory-Based Multilayered Neural Network, IEEE Transactions on Circuits and Systems II: Express Briefs 56 (4) (2009) 305-309. doi : 10.1109/TCSII. 2009. 2015400.

URL http://ieeexplore.ieee.org/document/4801651/

[140] I. B. Yildiz, H. Jaeger, S. J. Kiebel, Re-visiting the echo state property, Neural Networks 35 (2012) 1-9. doi: 10.1016/j.neunet.2012.07. 005.

URL http://linkinghub.elsevier.com/retrieve/pii/ S0893608012001852

[141] S. Zheng, Y. Song, T. Leung, I. Goodfellow, Improving the robustness of deep neural networks via stability training, in: Proceedings of the IEEE Conference on Computer Vision and Pattern Recognition, 2016, pp. 4480-4488.

[142] C. Wang, W. Zhao, Z. Luan, Q. Gao, K. Deng, Decoupling control of vehicle chassis system based on neural network inverse system, Mechanical Systems and Signal Processing 106 (2018) 176-197. doi:10.1016/j.ymssp. 2017.12.032.

URL http://linkinghub.elsevier.com/retrieve/pii/ S0888327017306696

[143] L. Boulon, D. Hissel, A. Bouscayrol, M.-C. Pera, From Modeling to Control of a PEM Fuel Cell Using Energetic Macroscopic Representation, IEEE Transactions on Industrial Electronics 57 (6) (2010) 18821891. doi:10.1109/TIE. 2009.2026760.

URL http://ieeexplore.ieee.org/document/5166485/

[144] M. Shafiq, M. A. Shafiq, H. A. Yousef, Stability and Convergence Analysis of Direct Adaptive Inverse Control, Complexity 2017 (2017) 1-12. doi : $10.1155 / 2017 / 7834358$.

URL https://www.hindawi.com/journals/complexity/2017/ 7834358/

[145] P. de Man, A. Preumont, Hybrid feedback-feedforward control for vibration suppression, Journal of Structural Control 3 (1-2) (1996) 33-44. doi: $10.1002 /$ stc. 4300030104 .

URL http://doi.wiley.com/10.1002/stc. 4300030104

[146] L. dos Santos Coelho, M. W. Pessa, Nonlinear identification using a B-spline neural network and chaotic immune approaches, Mechanical Systems and Signal Processing 23 (8) (2009) 2418-2434. doi:10.1016/j.ymssp. 2009.01.013.

URL http://linkinghub.elsevier.com/retrieve/pii/ S0888327009000090

[147] F.-Y. Wang, H. Zhang, D. Liu, Adaptive Dynamic Programming: An Introduction, IEEE Computational Intelligence Magazine 4 (2) (2009) 39-47. doi:10.1109/MCI . 2009.932261. URL http://ieeexplore.ieee.org/document/4840325/

[148] F. Lewis, D. Vrabie, Reinforcement learning and adaptive dynamic programming for feedback control, IEEE Circuits and Systems Magazine 9 (3) (2009) 32-50. doi : 10.1109/MCAS . 2009.933854. URL http: //ieeexplore.ieee.org/document/5227780/

[149] P. Saratchandran, Dynamic programming approach for multilayer neural network optimization, in: Neural Networks, 1991., IJCNN-91-Seattle International Joint Conference on, Vol. 1, IEEE, 1991, pp. 397-402.

[150] N. Wu, H. Wang, Deep learning adaptive dynamic programming for real time energy management and control strategy of micro-grid, Journal of Cleaner Production 204 (2018) 1169-1177. doi:10.1016/j.jclepro.2018.09.052.

URL https://linkinghub.elsevier.com/retrieve/pii/ S0959652618327665

[151] A. Visioli, Research trends for PID controllers, Acta Polytechnica 52 (5).

[152] M. Kishnani, S. Pareek, D. R. Gupta, Optimal Tuning of PID Controller Using Meta Heuristic Approach (2014) 6.

[153] S. V. Narvekar, V. K. Upadhye, Review of PI and PID Controllers, International Journal of Recent Trends in Engineering \& Research 2 (6).

[154] M. A. Henson, D. E. Seborg, Feedback Linearizing Control, in: Nonlinear Process Control, 1996.

[155] M. Noorkami, J. B. Robinson, Q. Meyer, O. A. Obeisun, E. S Fraga, T. Reisch, P. R. Shearing, D. J. Brett, Effect of temperature uncertainty on polymer electrolyte fuel cell performance, International Journal of Hydrogen Energy 39 (3) (2014) 1439-1448. doi:10.1016/j.ijhydene.2013.10.156 
URL http://linkinghub.elsevier.com/retrieve/pii/ S0360319913026712

[156] J. T. Pukrushpan, A. G. Stefanopoulou, H. Peng, Control of Fuel Cell Breathing: Initial Results on the Oxygen Starvation Problem.

[157] C. Dpature, P. Sicard, A. Bouscayrol, W. Lhomme, L. Boulon, Comparison of Backstepping Control and Inversion-Based Control of a Range Extender Electric Vehicle. 